\title{
Pb-oxo Interactions in Uranyl Hybrid Materials: a Combined Experimental and Computational Analysis of Bonding and Spectroscopic Properties
}

Dominique M. Brager, ${ }^{\mathrm{a}}$ Aaron D. Nicholas, ${ }^{\mathrm{a}}$ Mark H. Schofield, ${ }^{\mathrm{a}}$ Christopher L. Cahill ${ }^{\mathrm{a}}$

${ }^{a}$ Department of Chemistry, The George Washington University, $80022^{\text {nd }}$ Street, NW, Washington, DC, 20052, USA.

\begin{abstract}
Reported are the syntheses and characterization of six new heterometallic $\mathrm{UO}_{2}{ }^{2+} / \mathrm{Pb}^{2+}$ compounds. These materials feature rare instances of M-oxo interactions, which influence bonding properties of the uranyl cation. The spectroscopic effects of these interactions were measured using diffuse reflectance, luminescence and Raman spectroscopy. Computational density functional theory (DFT) based natural bonding orbital (NBO) and quantum theory of atoms in molecules (QTAIM) methods indicate interactions arise predominantly through charge transfer between cationic units via the electron donating uranyl $\mathrm{O} s p^{x}$ lone pair orbitals and electron accepting $\mathrm{Pb}^{2+}$ $p$ orbitals. The interaction strength varies as a function of $\mathrm{Pb}$-oxo interaction distance and angle with energy values ranging from ranging from $0.47 \mathrm{kcal} / \mathrm{mol}$ in the longer contacts to 21.94 $\mathrm{kcal} / \mathrm{mol}$ in the shorter contacts. Uranyl units with stronger interactions display an asymmetric bond weakening and a loss of covalent character in the $\mathrm{U}=\mathrm{O}$ bonds interacting closely with the $\mathrm{Pb}^{2+}$ ion. Luminescence quenching is observed in cases where strong $\mathrm{Pb}$-oxo interactions are present, and is accompanied by significant red-shifting of the uranyl symmetric Raman stretch. Changes to inner sphere uranyl bonding manifest as a weakening of the $\mathrm{U}=\mathrm{O}$ bond as a result of interaction with the $\mathrm{Pb}^{2+}$ ion.
\end{abstract}

\section{Introduction}

Heterometallic uranyl hybrid materials constitute an area of growing interest as the secondary metals in these materials allow for architectural diversity and can have effects on a wide range of physical properties including photochemistry and magnetism..${ }^{1-3}$ Recent work has shown that these secondary metal centers can form interactions with the nominally terminal uranyl-oxo groups, and that these interactions can influence the chemical bonding, spectroscopic and structural properties of these compounds. ${ }^{1,-8}$ Indeed, researchers have been motivated by efforts to improve the redox reactivity of the $\mathrm{UO}_{2}{ }^{2+}$ cation by functionalizing the uranyl-oxo for the purposes of waste stewardship. ${ }^{9-17}$

We are particularly interested in studying the impact of closed-shell secondary metal cations such as $\mathrm{Ag}^{++} \mathrm{Cd}^{2+}$, or $\mathrm{Pb}^{2+}$ on uranyl bonding and subsequent spectroscopic properties. A search of the Cambridge Structural Database (CSD) (needs citation) reveals 1900 heterometallic, uranyl bearing compounds featuring either main group or transition metal elements. Of these heterometallic structures, only 120 contain closed shell-metals, ${ }^{18}$ with the bulk featuring either $\mathrm{Ag}^{+}$ (46 compounds) or $\mathrm{Pb}^{2+}$ (31 compounds). These compounds display a range of luminescence behavior including, in some, a complete quenching of emission signatures. ${ }^{19-24}$ Looking deeper 
into the structural features of these compounds reveals that quenched luminescence is more common in complexes with close M-oxo interactions.

The quenching of uranyl emission by metal ions in the solid state is not without precedence. In the presence of open-shell transition metals such as $\mathrm{Cu}^{2+}, \mathrm{Fe}^{2+}$, and $\mathrm{Ni}^{2+}$ the uranyl emission signature is quenched owing to overlap of emission from the uranyl cation with the d-d absorption band of the metal allowing for energy transfer and non-radiative decay. ${ }^{25-29}$ Closed-shell metals $\left(\mathrm{Pb}^{2+}\right.$ and $\mathrm{Ag}^{+}$in particular) are also capable of quenching uranyl, yet these metals have filled atomic subshells, making $\mathrm{d} \rightarrow \mathrm{d}$ deactivation of uranyl emission not possible. An alternative explanation for the loss in intensity remains elusive, and as such there is an opportunity to probe this disruption in the emission pathway within these materials. ${ }^{19-21,23,24,30,31}$

The Raman spectra of these materials is also impacted by the presence of closed-shell secondary metal cations. Uranyl compounds have Raman spectra characterized by the presence of the $v_{1}$ symmetric stretch which, while sensitive to the coordination environment of the uranyl, is most commonly found in the range of 840 to $870 \mathrm{~cm}^{-1} \cdot{ }^{32-35}$ Previous work done by Arnold et al. found that red-shifting of the uranyl Raman stretch occurs as a consequence of close M-oxo interactions. ${ }^{9}$ The degree of shifting and $\mathrm{U}=\mathrm{O}$ bond weakening has been linked to the Lewis acidity of the coordinating metal, where less polarizable Group 1 metals cause much larger $\mathrm{U}=\mathrm{O}$ bond asymmetry as compared to post-transition metals. ${ }^{14}$ Carter et al. also recently demonstrated that silver cations participating in meaningful interaction with oxo groups give rise to weakened $\mathrm{U}=\mathrm{O}$ bonding signified by a red-shifting in the Raman $\mathrm{U}=\mathrm{O}$ symmetric stretch. ${ }^{8}$

We present herein a family of six novel heterometallic $\mathrm{Pb}^{2+} / \mathrm{UO}_{2}{ }^{2+}$ compounds featuring a range of $\mathrm{Pb}$-oxo distances and interaction strengths. We observed that $\mathrm{Pb}$-oxo interactions lead to quenching of the characteristic uranyl emission in compounds with close interactions, suggesting a change in the emissive profile to include a non-radiative pathway. Computational analysis determined that the $\mathrm{Pb}$-oxo interaction occurs as a result of charge transfer from the $\mathrm{O} s p^{x}$ and $\mathrm{U}=\mathrm{O} \sigma$ bonding into the $\mathrm{Pb} p$ orbitals and from the $\mathrm{Pb} s$ into the $\mathrm{U} 5 f$ and $\mathrm{U}=\mathrm{O} \sigma^{*}$ anti-bonding orbitals. As Pb-oxo distance decreases, the interaction energy between these orbital pairs as increases exponentially. The involvement of $\mathrm{U}=\mathrm{O} \sigma$ bonding and $\sigma^{*}$ anti-bonding orbitals in these interactions leads to a loss of covalent character and weakening of the $\mathrm{U}=\mathrm{O}$ bond which, in turn, results in a red-shifting of the $\mathrm{U}=\mathrm{O}$ symmetric stretch in the Raman spectra in complexes with short Pb-oxo contacts.

\section{Experimental Section}

General. Caution: Whereas the uranyl nitrate hexahydrate $\left[\mathrm{UO}_{2}\left(\mathrm{NO}_{3}\right)_{2}\right] \cdot 6 \mathrm{H}_{2} \mathrm{O}$ and uranyl acetate dihydrate $\left[\mathrm{UO}_{2}\left(\mathrm{CH}_{3} \mathrm{COO}\right)_{2}\right] \cdot 2 \mathrm{H}_{2} \mathrm{O}$ used in this study consists of depleted $\mathrm{U}$, standard precautions for handling radioactive and toxic substances should be followed.

All organic materials, diglycolic acid (digly) (Sigma Aldrich, 98\%), 1,2,3-benzenetricarboxylic acid (1,2,3-btca) (Acros Organics, 97\%), 2,2';6',2"-terpyridine (tpy) (Sigma Aldrich, 98\%), 2,6pyridinedicarboxylic acid (2,6-pdca) (Sigma Aldrich, 99\%), 1,10-phenanthroline (phen) (Alfa 
Aesar, 99\%), 1,4-phenylenediacetic acid (pda) (Sigma Aldrich, 97\%), 1,2,4,5benzenetetracarboxylic acid (1,2,4,5-btca) (Acros Organics, 96\%), and 2,2'bipyrimidine (bypm) (Sigma Aldrich, 95\%), were purchased and used as received. $\mathrm{Pb}\left(\mathrm{NO}_{3}\right)_{2}$ (Sigma Aldrich, 99.9+\%) is also commercially available and was used without further modification.

\section{Synthesis}

All complexes reported herein were synthesized via solvothermal methods, compounds $\mathbf{1}, \mathbf{2}, \mathbf{5}$, and $\mathbf{6}$ in a $23 \mathrm{~mL}$ Teflon-lined Parr autoclave, and $\mathbf{3}$ and $\mathbf{4}$ in a tightly capped 10mL vial in a sand bath. The ratios of reagents used, reaction temperature, and solvent system used are summarized in Table 1. Ratios for reagents were optimized for crystal growth and purity. All six compounds were rinsed with ethanol and water to yield pure samples, with the exception of compound $\mathbf{3}$, which contained an unidentified phase.

Table 1. Summary of synthesis conditions of complexes 1-6.

\begin{tabular}{|c|c|c|c|c|c|}
\hline Compound & Ligand & Cap & $\begin{array}{l}\text { Temperature } \\
\left({ }^{\circ} \mathrm{C}\right)\end{array}$ & $\begin{array}{l}\text { Ratio } \\
\text { Ligand:Cap:U:Pb }\end{array}$ & Solvent \\
\hline 1 & Diglycolic Acid & N/A & 150 & $10: 0: 4: 10$ & $3 \mathrm{~mL}$ Water \\
\hline 2 & $\begin{array}{l}1,2,3- \\
\text { benzenetricarboxylic } \\
\text { acid }\end{array}$ & $\begin{array}{l}2,2^{\prime} ; 6^{\prime}, 2^{\prime \prime}- \\
\text { terpyridine }\end{array}$ & 110 & $1: 1: 2: 2$ & $\begin{array}{l}0.75 \mathrm{~mL} \text { DMF } \\
2.25 \mathrm{~mL} \text { Water }\end{array}$ \\
\hline 3 & $\begin{array}{l}\text { 2,6-pyridinedicarboxylic } \\
\text { acid }\end{array}$ & $\begin{array}{l}1,10- \\
\text { phenanthroline }\end{array}$ & 110 & $2: 2: 2: 1$ & $\begin{array}{l}0.2 \mathrm{~mL} \text { DMF } \\
0.7 \mathrm{~mL} \text { Water }\end{array}$ \\
\hline 4 & $\begin{array}{l}\text { 2,6-pyridinedicarboxylic } \\
\text { acid }\end{array}$ & N/A & 140 & $1: 0: 1: 2$ & $3 \mathrm{~mL}$ Water \\
\hline 5 & $\begin{array}{l}1,2,4,5- \\
\text { benzenetetracarboxylic }\end{array}$ & $\begin{array}{l}2,2^{\prime}- \\
\text { bipyrimidine }\end{array}$ & 110 & $1: 1: 1: 1$ & $\begin{array}{l}0.75 \mathrm{~mL} \text { DMF } \\
2.25 \mathrm{~mL} \text { Water }\end{array}$ \\
\hline 6 & $\begin{array}{l}\text { 1,4-phenylenediacetic } \\
\text { acid }\end{array}$ & $\begin{array}{l}2,2^{\prime} ; 6^{\prime}, 2^{\prime \prime}- \\
\text { terpyridine }\end{array}$ & 110 & $1: 1: 1: 1$ & $\begin{array}{l}0.75 \mathrm{~mL} \text { DMF } \\
2.25 \mathrm{~mL} \text { Water }\end{array}$ \\
\hline
\end{tabular}

X-ray Crystallography. Single crystals from each bulk sample were isolated and mounted on MiTeGen micromounts. Data were collected on a Bruker D8 Quest equipped with a Photon II detector, using a Mo Ka source. Reflection data were collected using $0.5^{\circ} \omega$ and $\varphi$ scans at $100(2)$ $\mathrm{K}$. The APEX III software suite ${ }^{36,37}$ was used for integrating the data then performing an absorption correction, which incorporates both $\mathrm{SAINT}^{38}$ and SADABS. ${ }^{39}$ Structure solutions (obtained using intrinsic phasing), and refinement were performed using the ShelXT package ${ }^{40}$ and ShelXL ${ }^{41}$ in APEX III. ${ }^{38}$ All non-hydrogen atoms were located using Fourier difference maps and refined anisotropically. Hydrogen atoms were placed in ideal locations using HFIX33 for methyl groups, and HFIX43 for aromatic hydrogen atoms, allowing hydrogen atoms to ride on their parent atoms. All figures were prepared with Crystal Maker 8.2.2. ${ }^{42}$ Data collection and refinement details for 1-6 are included in Table 2.

Compound 2 displayed unusually large residual electron density in the $\mathrm{C}-\mathrm{C}$ bond between $\mathrm{C} 7$ and C9. Multiple experiments were run on different crystals of Compound $\mathbf{2}$ which all displayed 
the same large residual electron density. The data does not show evidence of twinning or space group discrepancies and attempts to model the ligand as disordered were unsuccessful.

Powder X-Ray Diffraction. Powder X-Ray Diffraction (PXRD) data on the bulk reaction products of compounds 1-6 (Figures S1-6, SI) were used to gauge the purity of the preparations. All data were collected on a Rigaku Miniflex $\left(\mathrm{Cu} \mathrm{K} \alpha, 2 \theta=3-60^{\circ}\right)$ and were analyzed using the Match! software program. ${ }^{43}$ The syntheses of 2 and 4-6 yielded products free of impurities, yet $\mathbf{1}$ contains an unidentified diffraction peak at $8.9^{\circ}$ and $\mathbf{3}$ contains unidentified diffraction peaks at $9.9^{\circ}, 11.1^{\circ}$, and $14.7^{\circ}$.

Table 2. Crystallographic Refinement Details for Compounds $1-6 .{ }^{a}$

\begin{tabular}{|c|c|c|c|}
\hline & 1 & 2 & 3 \\
\hline CCDC no. & 2064213 & 2064214 & 2064215 \\
\hline Formula & {$\left[\mathrm{UO}_{2} \mathrm{~Pb}\left(\mathrm{C}_{4} \mathrm{H}_{4} \mathrm{O}_{5}\right)_{2}\left(\mathrm{H}_{2} \mathrm{O}\right)\right] \cdot\left(\mathrm{H}_{2} \mathrm{O}\right)$} & {$\left[\mathrm{UO}_{2} \mathrm{~Pb}\left(\mathrm{C}_{15} \mathrm{H}_{11} \mathrm{~N}_{3}\right)\left(\mathrm{C}_{9} \mathrm{H}_{6} \mathrm{O}_{6}\right)\left(\mathrm{NO}_{3}\right)\right]$} & {$\left[\mathrm{UO}_{2} \mathrm{~Pb}\left(\mathrm{C}_{15} \mathrm{H}_{11} \mathrm{~N}_{3}\right)\left(\mathrm{C}_{9} \mathrm{H}_{6} \mathrm{O}_{6}\right)\left(\mathrm{NO}_{3}\right)\right]$} \\
\hline Formula weight & 777.41 & 979.62 & 912.57 \\
\hline Crystal System & Triclinic & Triclinic & Triclinic \\
\hline Space Group & $\mathrm{P}-1$ & $\mathrm{P}-1$ & $\mathrm{P}-1$ \\
\hline a, $\AA$ & $7.8698(6)$ & $8.9530(4)$ & $7.1919(2)$ \\
\hline $\mathrm{b}, \AA$ & $9.2871(8)$ & $11.2200(5)$ & 12.0851(3) \\
\hline $\mathrm{c}, \AA$ & $11.3246(9)$ & $13.0939(6)$ & $14.3154(4)$ \\
\hline$\alpha,^{\circ}$ & $71.603(2)$ & $69.263(1)$ & $66.723(1)$ \\
\hline$\beta,^{\circ}$ & $83.481(2)$ & $78.099(1)$ & $85.576(1)$ \\
\hline$\gamma,{ }^{\circ}$ & $70.411(2)$ & $66.732(1)$ & $76.232(1)$ \\
\hline Volume, $\AA^{3}$ & $739.90(10)$ & $1212.73(9)$ & $1109.91(5)$ \\
\hline$Z$ & 2 & 2 & 2 \\
\hline$\rho_{\text {calc }}, \mathrm{g} \mathrm{cm}^{-3}$ & 3.490 & 2.683 & 2.731 \\
\hline$\mu, \mathrm{mm}^{-1}$ & 22.369 & 13.675 & 14.926 \\
\hline Radiation & 0.71073 & 0.71073 & 0.71073 \\
\hline Temp., K & 100 & 100 & 100 \\
\hline residuals: ${ }^{\mathrm{a}} \mathrm{R} ; \mathrm{R}_{\mathrm{w}}$ & $0.0145,0.0333$ & $0.0357,0.0757$ & $0.0206,0.0509$ \\
\hline \multirow[t]{2}{*}{ Goodness of fit } & 1.077 & 1.033 & 1.057 \\
\hline & 4 & 5 & 6 \\
\hline CCDC no. & 2064216 & 2064217 & 2064218 \\
\hline Formula & {$\left[\mathrm{UO}_{2} \mathrm{~Pb}_{2}\left(\mathrm{C}_{7} \mathrm{H}_{5} \mathrm{NO}_{4}\right)_{2}\left(\mathrm{NO}_{3}\right)_{2}\right] \cdot 2\left(\mathrm{H}_{2} \mathrm{O}\right)$} & {$\left[\mathrm{UO}_{2} \mathrm{~Pb}\left(\mathrm{C}_{8} \mathrm{H}_{6} \mathrm{~N}_{4}\right)\left(\mathrm{C}_{10} \mathrm{H}_{2} \mathrm{O}_{8}\right)\right] \cdot 2\left(\mathrm{H}_{2} \mathrm{O}\right)$} & {$\left[\mathrm{UO}_{2} \mathrm{~Pb}\left(\mathrm{C}_{15} \mathrm{H}_{11} \mathrm{~N}_{3}\right)\left(\mathrm{C}_{10} \mathrm{H}_{10} \mathrm{O}_{4}\right)_{4}\right]$} \\
\hline Formula weight & 1157.57 & 917.51 & 1094.83 \\
\hline Crystal System & Triclinic & Monoclinic & Orthorhombic \\
\hline Space Group & $\mathrm{P}-1$ & $\mathrm{P} 2 / \mathrm{n}$ & Pbca \\
\hline $\mathrm{a}, \AA$ & $6.8263(4)$ & $9.3880(3)$ & $12.1462(3)$ \\
\hline $\mathrm{b}, \AA$ & $8.5430(6)$ & $10.8560(3)$ & $19.7804(5)$ \\
\hline $\mathrm{c}, \AA$ & $10.2476(7)$ & $11.5855(3)$ & $28.2944(8)$ \\
\hline$\alpha,^{\circ}$ & $69.388(2)$ & 90 & 90 \\
\hline$\beta,^{\circ}$ & $74.885(2)$ & $112.895(1)$ & 90 \\
\hline$\gamma,{ }^{\circ}$ & $71.102(2)$ & 90 & 90 \\
\hline Volume, $\AA^{3}$ & $521.89(6)$ & $1087.73(5)$ & $6797.9(3)$ \\
\hline$Z$ & 1 & 2 & 8 \\
\hline$\rho_{\text {calc }}, \mathrm{g} \mathrm{cm}^{-3}$ & 3.683 & 2.801 & 2.139 \\
\hline$\mu, \mathrm{mm}^{-1}$ & 23.932 & 15.239 & 9.768 \\
\hline Radiation & 0.71073 & 0.71073 & 0.71073 \\
\hline Temp., K & 100 & 100 & 100 \\
\hline residuals: ${ }^{\mathrm{a}} \mathrm{R} ; \mathrm{R}_{\mathrm{w}}$ & $0.0260,0.0668$ & $0.0205,0.0382$ & $0.0208,0.0365$ \\
\hline Goodness of fit & 1.119 & 1.109 & 1.048 \\
\hline
\end{tabular}


Optical Measurements. Diffuse reflectance spectra were collected on single crystals at $298 \mathrm{~K}$. A Mikropack DH-2000-BAL deuterium and halogen light source was used, coupled with an Ocean Optics Flame detector. Scattered light was collected with a fiber-optic cable and spectra were referenced with $\mathrm{BaSO}_{4}$. Data were processed using OceanView spectroscopy software. Tauc plots of reflection data can be found in the Electronic Supplementary Information. Steady-state luminescence scans of 1-6 were collected at $298 \mathrm{~K}$ and $78 \mathrm{~K}$. Spectra were collected with a Fluorolog®-3 photoluminescence spectrophotometer from Horiba using a $450 \mathrm{~W}$ xenon arc lamp combined with a double excitation monochromator and double emission monochromator. A photomultiplier tube at $950 \mathrm{~V}$ was used as the emission detector. Low temperature luminescence measurements were collected on solid samples under vacuum using a Janis VPF-100 cryostat equipped with UV-grade fused silica windows coupled with a Lakeshore model 325 temperature controller. Single crystal samples were mounted on a quartz plate using non-emitting high vacuum grease. Raman spectra of single crystals of 1-6 were collected using a HORIBA LabRAM HR Evolution Raman Microscope over the 150-3000 $\mathrm{cm}^{-1}$ range. An excitation line at $405 \mathrm{~nm}$ was used for each collection.

\section{Computational details.}

Natural Bond Orbitals (NBO) and Quantum Theory of Atoms in Molecules (QTAIM). The uranyl-cation interactions in 1-6 between the $\mathrm{UO}_{2}{ }^{2+}$ and $\mathrm{Pb}^{2+}$ units were investigated and quantified via natural bond orbital (NBO) analysis using Gaussian $16 .{ }^{44} \mathrm{NBO}$ calculations were performed using NBO7 on molecular models of 1-6 constructed from crystallographic fragments consisting of the shortest $\mathrm{U}=\mathrm{O} \cdots \mathrm{Pb}$ distance and all the ligands coordinated to those metals. Both the $\mathrm{B} 3 \mathrm{LYP}{ }^{45,46}$ functional with the modified scalar-relativistic effective core potential (ECP) basis set DEF2TZVP ${ }^{47,48}$ and associated pseudopotential for all non-U atoms was implemented in the software was used throughout. ECP60MWB_SEG valence basis set was used for all U atoms. ${ }^{49-51}$ NBO second order perturbation theory (SOPT) was applied to (i) quantify the magnitude of the interaction (in $\mathrm{kcal} / \mathrm{mol}$ ) between the donor and acceptor and (ii) identify the atomic or molecular orbitals involved. Quantum theory of atoms in molecules ${ }^{51}$ (QTAIM) analysis of bonding properties at the bond critical points (BCPs) was performed in the AIMA11 software suite ${ }^{52}$ using the DFT converged wavefunction. Models generated and used for NBO and AIMA11 calculations can be found in the SI. Computations were carried out on an additional 10 structures reported by Thuery et. al. ${ }^{19-22,24}$ (CSD Refcodes: AYAVED, AYAVEZ, BEKPIT, GAPMOC, GAPPEV, OSOMOA, OSOMUG, OSONER, ZASJAH).

\section{Results and Discussion}

\section{Structural Descriptions.}

Compound 1, $\left[\mathrm{UO}_{2} \mathrm{~Pb}(\operatorname{digly})_{2}\left(\mathrm{H}_{2} \mathrm{O}\right)\right] \cdot\left(\mathrm{H}_{2} \mathrm{O}\right)$, crystallizes in the space group $P-1$ and the asymmetric unit contains a single crystallographically unique $\mathrm{UO}_{2}{ }^{2+}$ cation adopting a pentagonal bipyramidal geometry as well as one crystallographically unique seven-coordinate $\mathrm{Pb}^{2+}$ (Figure 1). 
The axial $\mathrm{U}=\mathrm{O}$ bonds have bond lengths of $1.779(3) \AA(\mathrm{O} 1)$ and $1.773(3) \AA(\mathrm{O} 2)$ with a $\angle \mathrm{O}-\mathrm{U}-\mathrm{O}$ of $179.2(1)^{\circ}$. The $\mathrm{UO}_{2}{ }^{2+}$ is coordinated in the equatorial plane by a tridentate diglycolate (via $\mathrm{O} 3$, $\mathrm{O} 5$, and $\mathrm{O6}$ ) which also coordinates to the $\mathrm{Pb}^{2+}$ cation via $\mathrm{O} 3$ and $\mathrm{O} 4$. The $\mathrm{Pb}^{2+}$ cation forms a tridentate coordination to another diglycolate via $\mathrm{O} 9, \mathrm{O} 10$, and $\mathrm{O} 11$. The oxygen atoms on the terminal carboxylate groups of this ligand each form a monodentate coordination to a $\mathrm{UO}_{2}{ }^{2+}$ on either side (O8 and O12). Each $\mathrm{Pb}^{2+}$ cation is also coordinated to a single water molecule (O13) which, in turn, forms hydrogen bonds to $\mathrm{O} 4$ and $\mathrm{O} 7$ on a diglycolate ligand. A lattice water (O14) hydrogen bonds to $\mathrm{O} 6$ and $\mathrm{O} 7$ on adjacent diglycolate ligands (Figure 2). The $\mathrm{Pb}^{2+}$ cation interacts with one of the oxo groups of the $\mathrm{UO}_{2}{ }^{2+}$ cation via $\mathrm{O} 1$ with a distance of 2.816(2) $\AA$ and a $\angle \mathrm{U}=\mathrm{O}$ $\mathrm{Pb}$ angle of $150.2(1)^{\circ}$. Packing of 1 (Figure 2) reveals 2-dimensional sheets in the (001) plane which are assembled together via hydrogen bonding interactions between the $\mathrm{Pb}^{2+}$ coordinated waters and the terminal carboxylate group of the diglycolate.

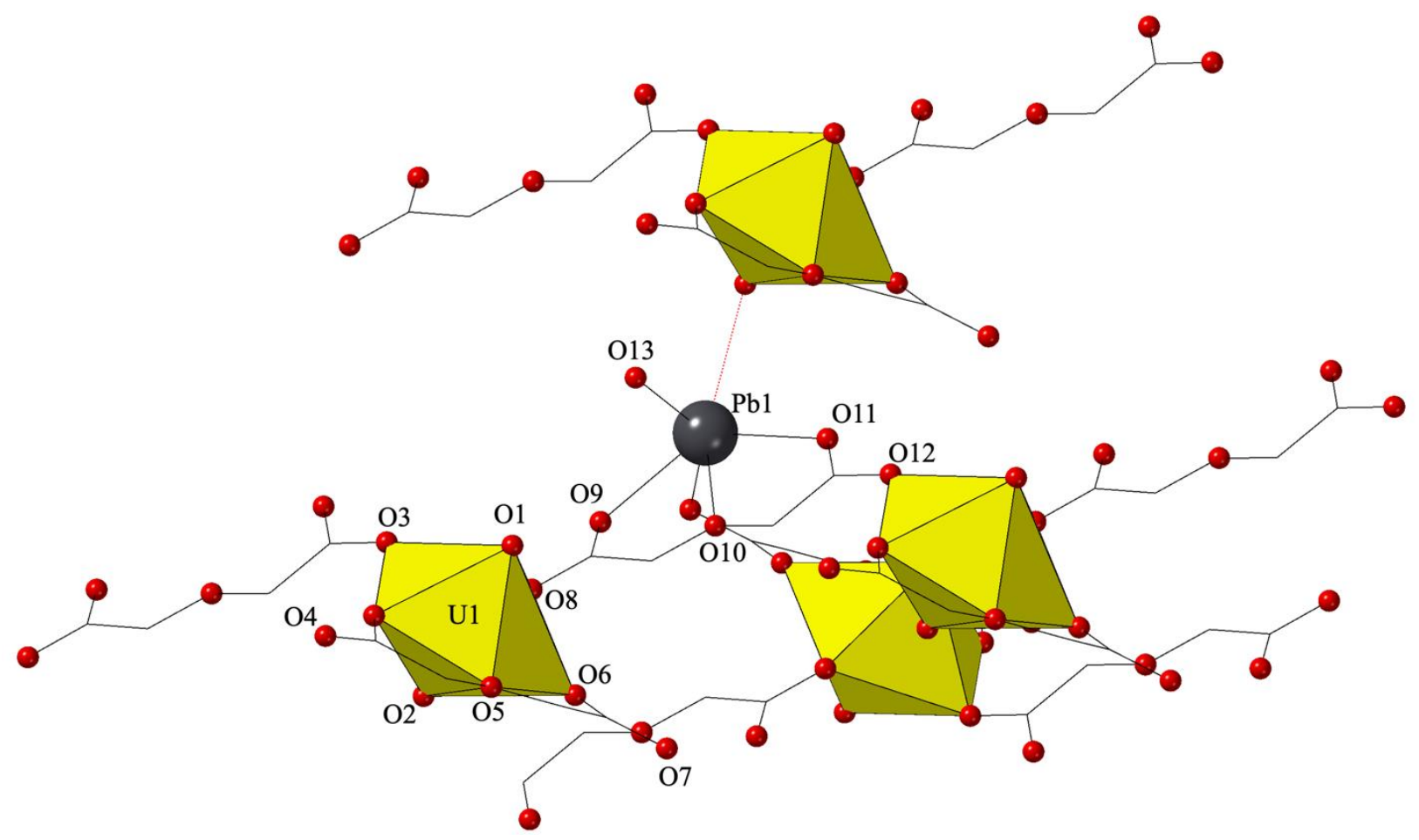

Figure 1. Local representation of compound 1 detailing the metal coordination environments. Uranyl polyhedra are shown in yellow; $\mathrm{Pb}$ and $\mathrm{O}$ are grey and red spheres respectively. Lead-oxo interaction depicted by a dotted red line. $\mathrm{H}$ atoms and lattice water have been omitted for clarity. 


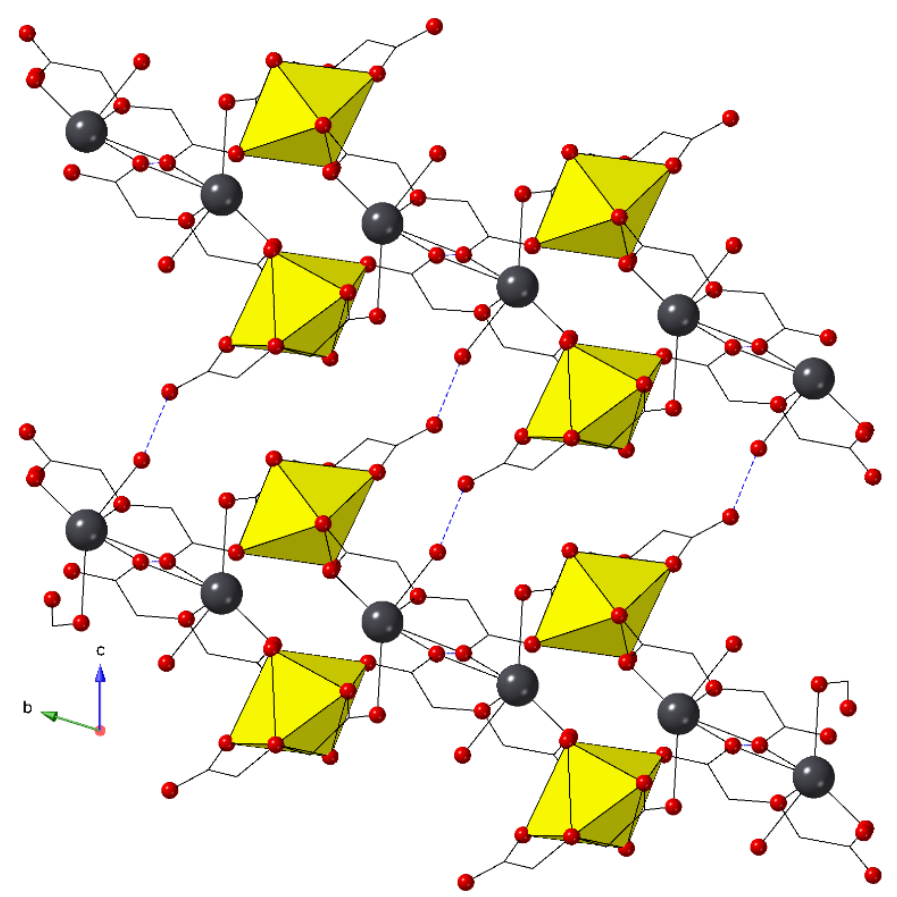

Figure 2. Global structure of 1 shown along the $a$-axis. The hydrogen bonding interactions between adjacent sheets via coordinated waters and diglycolate carboxylate groups are depicted by dotted blue lines.

Compound 2, $\left[\mathrm{UO}_{2} \mathrm{~Pb}\right.$ (tpy)(1,2,3-btca) $\left.\left(\mathrm{NO}_{3}\right)\right]$, crystallizes in the space group $P-1$ and the asymmetric unit features one crystallographically unique $\mathrm{UO}_{2}{ }^{2+}$ cation adopting a pentagonal bipyramidal geometry. It forms an edge-sharing dimeric species with an adjacent $\mathrm{UO}_{2}{ }^{2+}$ cation where it is bridged by a shared carboxylate oxygen (O7) (Figure 3). The axial $\mathrm{U}=\mathrm{O}$ bonds have bond lengths of 1.789(6) (O1) and 1.769(6) $\AA(\mathrm{O} 2)$ with a $\angle \mathrm{O}-\mathrm{U}-\mathrm{O}$ of $177.8(3)^{\circ}$. Each uranyl has three 1,2,3-benzenetricarboxylate ligands bound equatorially, one of which bridges the two $\mathrm{UO}_{2}{ }^{2+}$ cations through $\mathrm{O} 7$ and either $\mathrm{O} 3$ or $\mathrm{O} 5$. There is an additional monodentate equatorially bound 1,2,3-benzenetricarboxylate coordinated through one oxygen (O6) of a carboxylate group. The remaining oxygen of the carboxylate group (O5) coordinates to an adjacent dimer uranyl pair. There is also one crystallographically unique 7-coordinate $\mathrm{Pb}^{2+}$ cation which is capped on one side by a tridentate $2,2^{\prime} ; 6^{\prime}, 2^{\prime \prime}$-terpyridine. It forms an additional bidentate coordination to a nitrate group. The $\mathrm{Pb}^{2+}$ cation coordinates to the carboxylate $\mathrm{O} 8$ to complete the inner coordination sphere. The $\mathrm{Pb}^{2+}$ forms a close interaction with the axial uranyl oxo (O1) at a distance of 2.877(5) $\AA$ and a $\angle \mathrm{U}=\mathrm{O}-\mathrm{Pb}$ of $117.2(2)^{\circ}$. It also forms a close interaction with the equatorial uranyl $\mathrm{O} 3$ at a distance of 2.990(5) $\AA$. The uranyl dimers, which are linked through the O6/O5 carboxylate group, form double wide chains in the [100] direction (Figure 4) with the capped $\mathrm{Pb}^{2+}$ cations on oriented outward towards the space between the chains. 


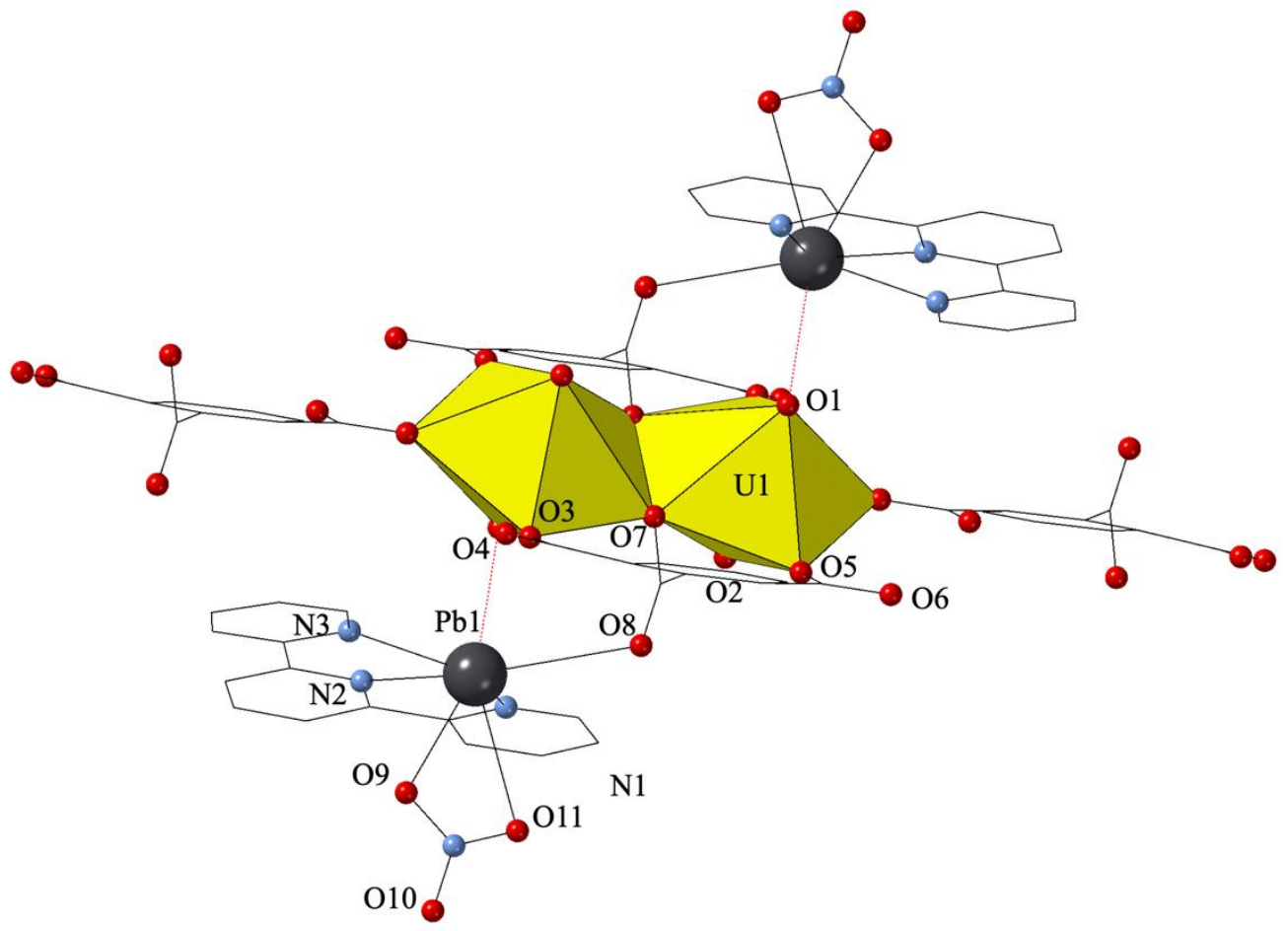

Figure 3. Local representation of compound $\mathbf{2}$ detailing the metal coordination environments. $\mathrm{N}$ atoms are shown as blue spheres. Pb-oxo interaction depicted by a dotted red line.

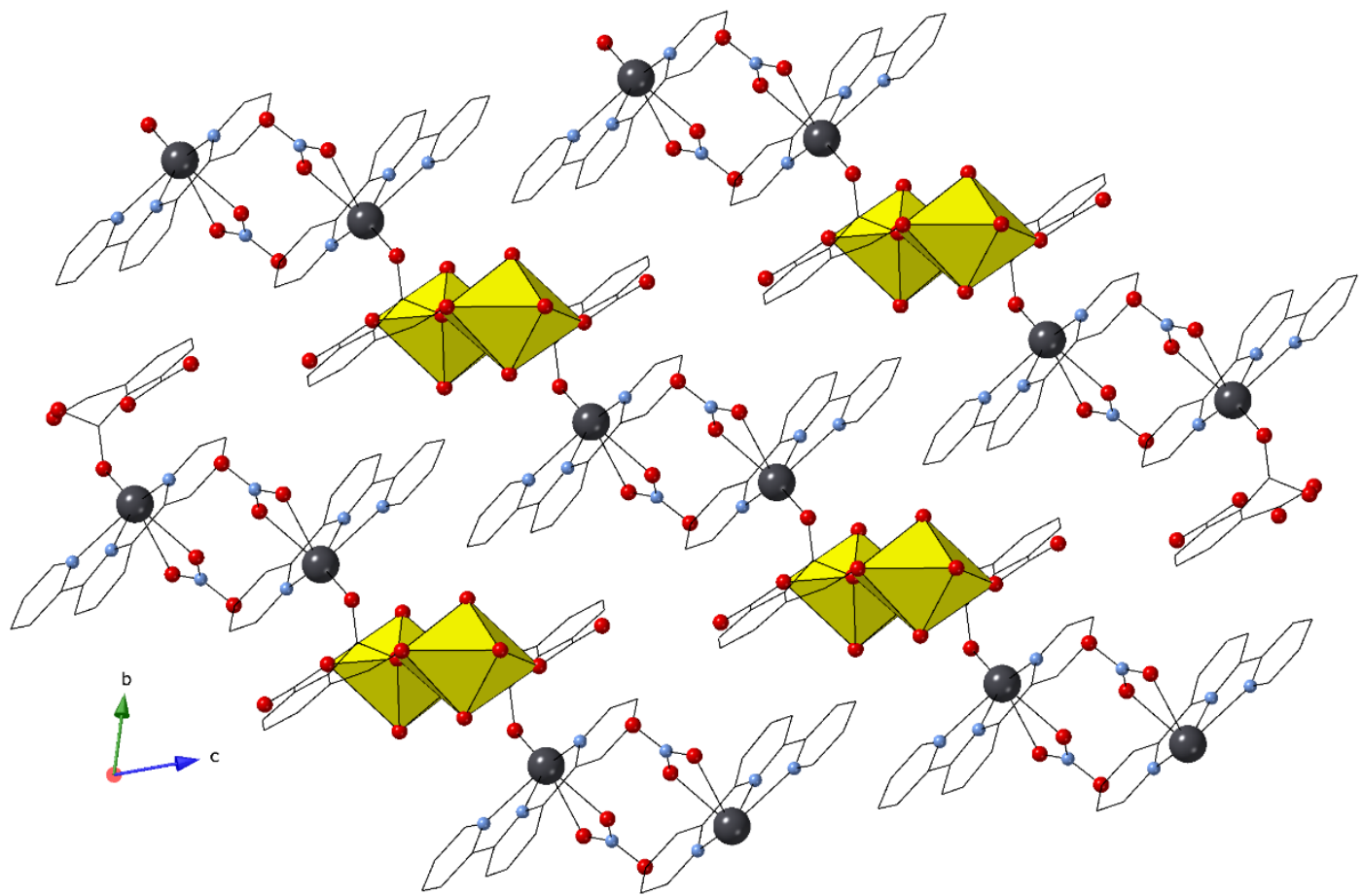

Figure 4. Global structure of compound 2 shown along the $a$-axis. 
Compound 3, $\left[\mathrm{UO}_{2} \mathrm{~Pb}(\right.$ phen $\left.)(2,6-\mathrm{pdca})\left(\mathrm{NO}_{3}\right)\right]$, crystallizes in the space group $P-1$ and the asymmetric unit contains one crystallographically unique $\mathrm{UO}_{2}{ }^{2+}$ cation adopting a pentagonal bipyramidal geometry, as well as a single crystallographically unique 7-coordinate $\mathrm{Pb}^{2+}$ cation. The axial $\mathrm{U}=\mathrm{O}$ bonds have bond lengths of $1.779(3) \AA(\mathrm{O} 1)$ and $1.770(3) \AA(\mathrm{O} 2)$ with a $\angle \mathrm{O}-\mathrm{U}-\mathrm{O}$ of $178.8(2)^{\circ}$. The $\mathrm{UO}_{2}{ }^{2+}$ cation is coordinated to a tridentate 2,6-pyridinedicarboxylate via $\mathrm{O} 3, \mathrm{O} 5$, and $\mathrm{N} 1$ and to two monodentate formate ions via $\mathrm{O} 7$ and $\mathrm{O} 9$ in the equatorial plane (Figure 5). The $\mathrm{Pb}^{2+}$ cation features a bidentate coordination to a 1,10-phenanthroline via to $\mathrm{N} 2$ and $\mathrm{N} 3$. It also forms a bidentate coordination to one of the carboxylate groups on the 2,6pyridinedicarboxylate ligand via $\mathrm{O} 3$ and $\mathrm{O} 4$. One of the formate molecules forms a bidentate coordination to the $\mathrm{Pb}^{2+}$ via $\mathrm{O} 9$ and $\mathrm{O} 10$, whereas the other forms a monodentate coordination via O8. These formate molecules serve as bridges between the $\mathrm{Pb}^{2+}$ cation and the $\mathrm{UO}_{2}{ }^{2+}$ cation forming 1-D chains along [100] (Figure 6). These chains assemble via $\pi$ - $\pi$ stacking between stacked 1,10-phenanthroline ligands in the [010] direction and the 2,6-pyridinedicarboxylate ligands in the [001] direction. Each $\mathrm{Pb}^{2+}$ cation forms an interaction with the axial oxo group of $\mathrm{UO}_{2}{ }^{2+}$ cation at a distance of 3.087(3) $\AA$ and a $\angle \mathrm{U}=\mathrm{O}-\mathrm{Pb}$ angle of $140.0(1)^{\circ}$.

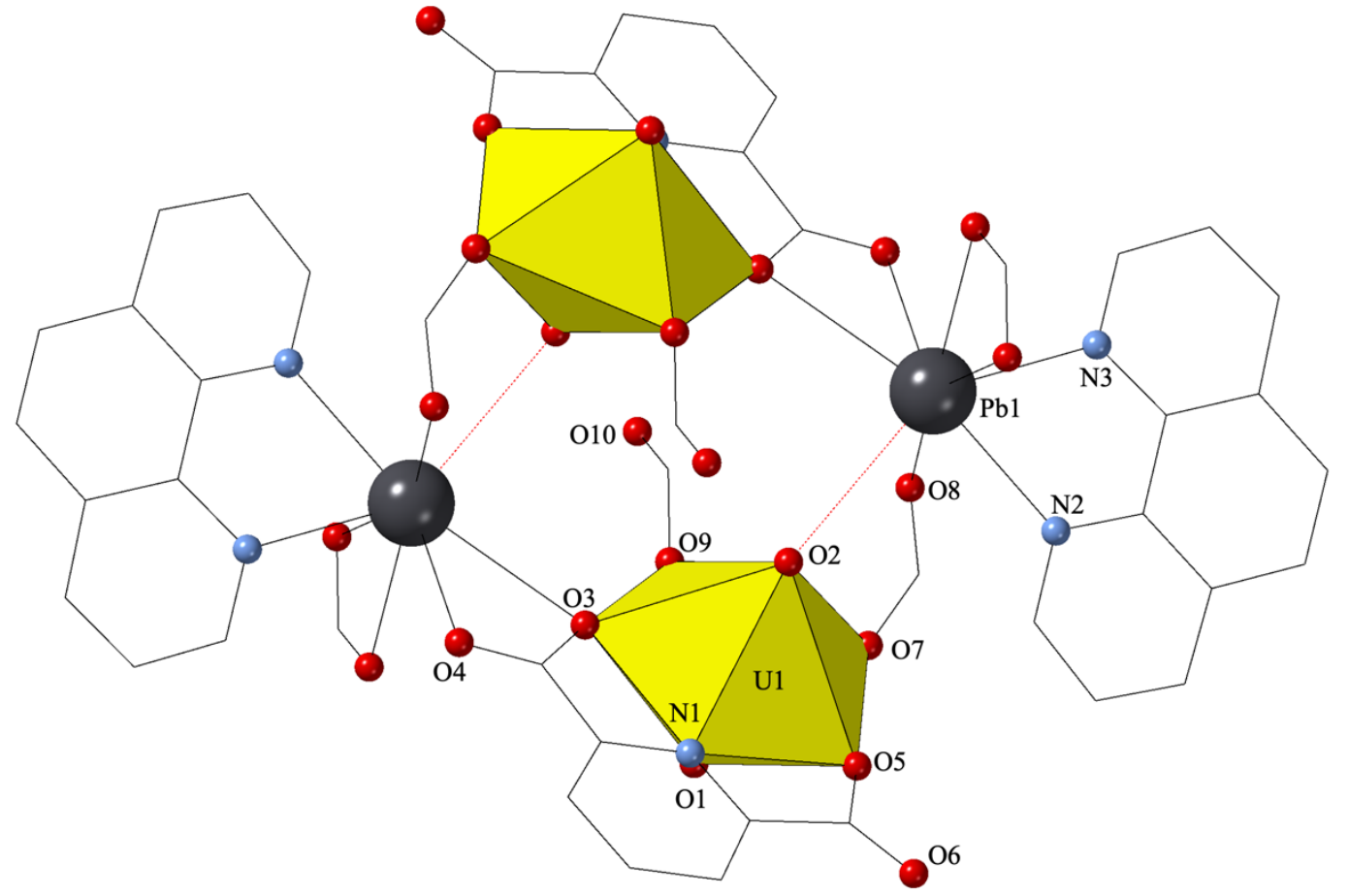

Figure 5. Local representation of compound $\mathbf{3}$ detailing the metal coordination environments. $\mathrm{Pb}-$ oxo interaction depicted by a dotted red line. 


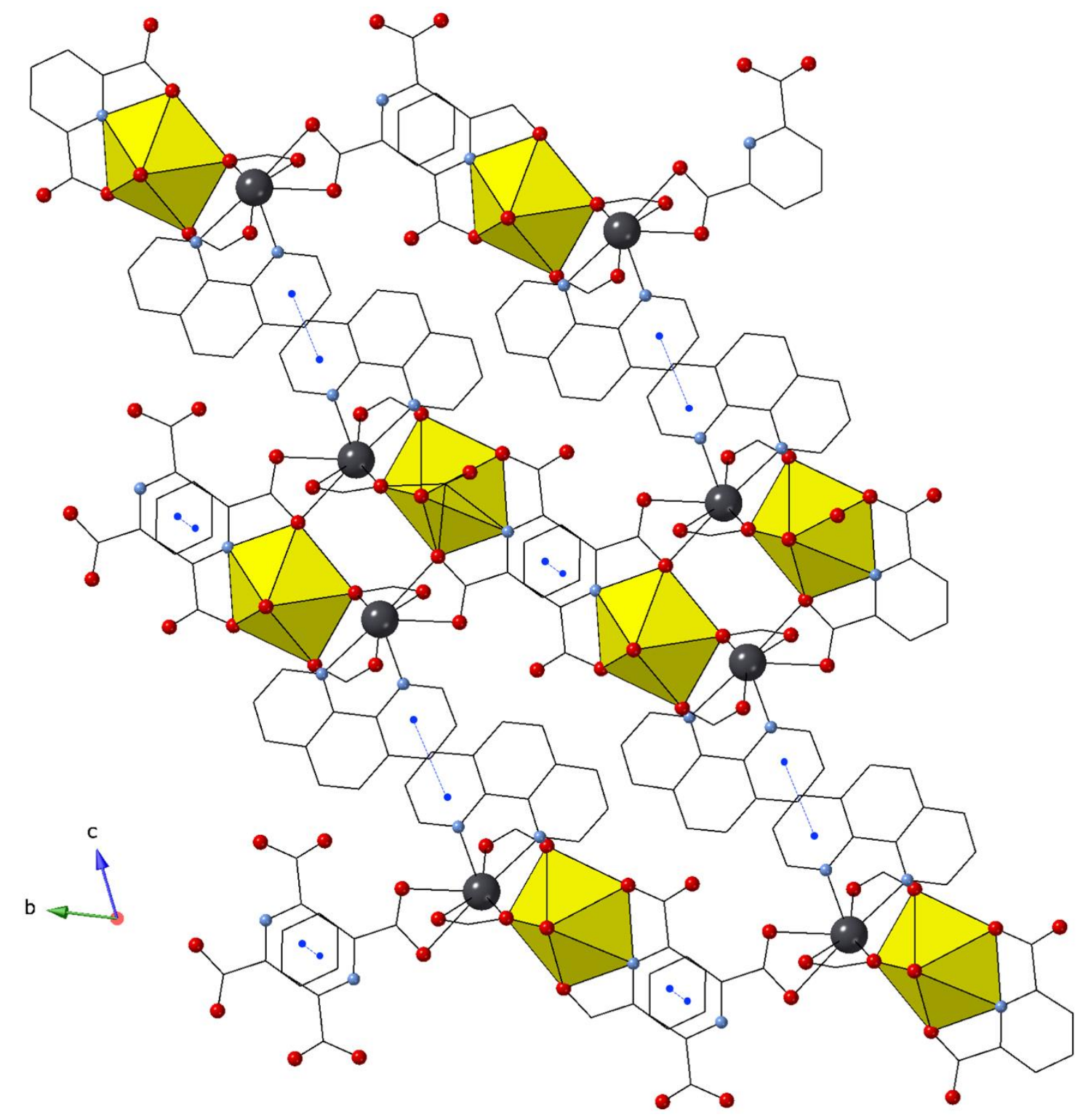

Figure 6. Global structure of compound $\mathbf{3}$ shown along the $a$-axis. $\pi$ - $\pi$ stacking is depicted by blue lines from ring centroids.

Compound 4, $\left[\mathrm{UO}_{2} \mathrm{~Pb}_{2}(2,6-\mathrm{pdca})_{2}\left(\mathrm{NO}_{3}\right)_{2}\right] \cdot 2\left(\mathrm{H}_{2} \mathrm{O}\right)$, crystallizes in the space group $P-1$ and the asymmetric unit contains one crystallographically unique $\mathrm{UO}_{2}{ }^{2+}$ cation adopting a hexagonal bipyramidal geometry, as well as a single crystallographically unique 7-coordinate $\mathrm{Pb}^{2+}$ cation. The $\mathrm{U}=\mathrm{O}$ bonds are generated through symmetry and have lengths of $1.756(1) \AA$ with a $\angle \mathrm{O}-\mathrm{U}-\mathrm{O}$ of $180^{\circ}$. The $\mathrm{UO}_{2}{ }^{2+}$ cation is coordinated to two tridentate 2,6-pyridinedicarboxylate in the equatorial plane (Figure 7). Each 2,6-pyridinedicarboxylate is coordinated to four $\mathrm{Pb}^{2+}$ cations via the carboxylate oxygens. The $\mathrm{Pb}^{2+}$ cation is coordinated to a water molecule as well as four 2,6pyridinedicarboxylate ligands forming bridges to the $\mathrm{UO}_{2}{ }^{2+}$ cations. The $\mathrm{Pb}^{2+}$ cation also coordinates to three nitrate groups which bridge to adjacent lead cations, forming a 3-dimensional network. In this network, the 2,6-pyridinedicarboxylates align to form $\pi$ - $\pi$ stacking interactions 
along the a-axis (Figure 8). There is no $\mathrm{Pb}$-oxo interaction as the $\mathrm{Pb}^{2+}$ is 4.467(4) $\AA$ away from the nearest oxo group; the $\angle \mathrm{U}=\mathrm{O}-\mathrm{Pb}$ angle is $71.9(1)^{\circ}$.

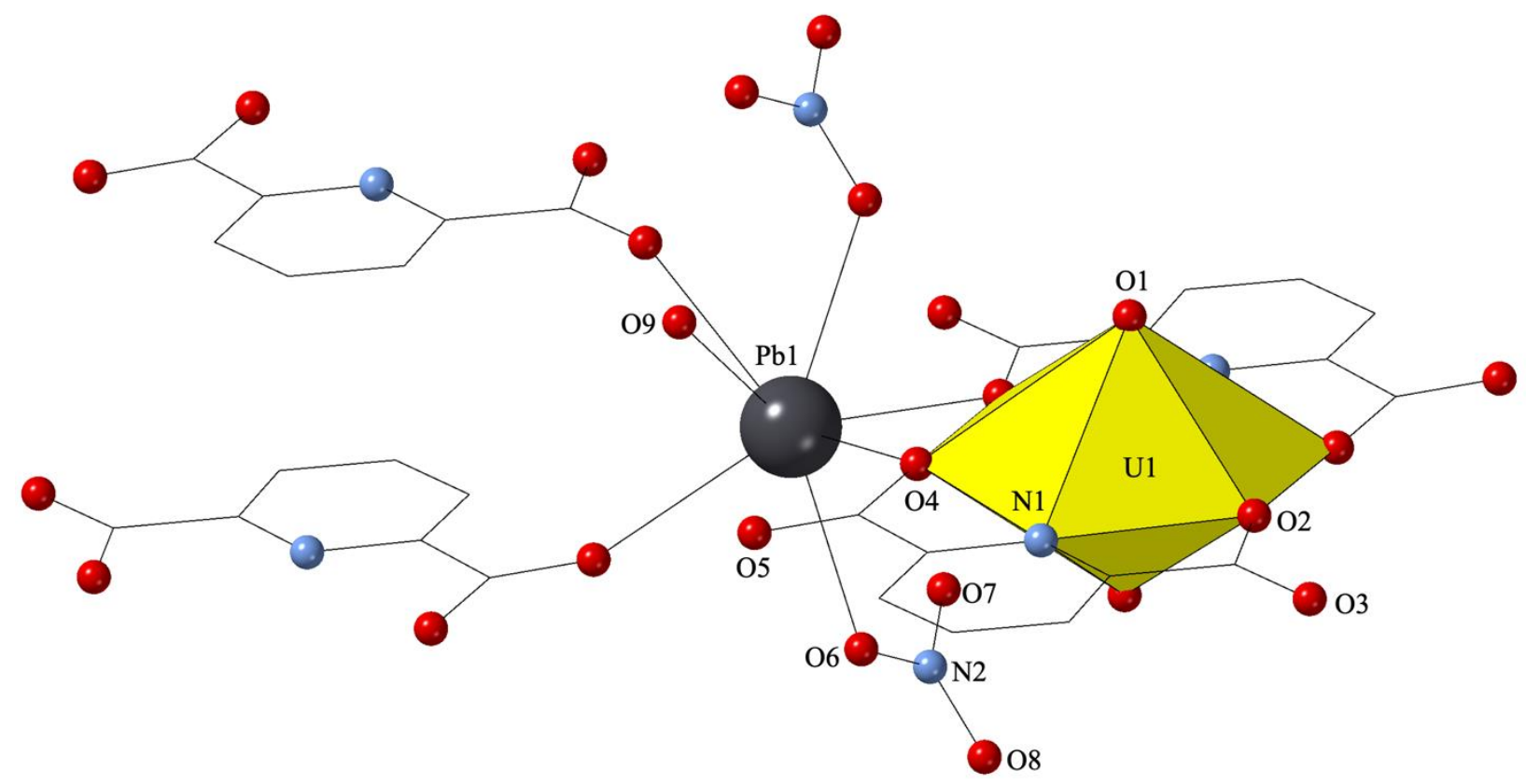

Figure 7. Local representation of compound $\mathbf{4}$ detailing the metal coordination environments. 


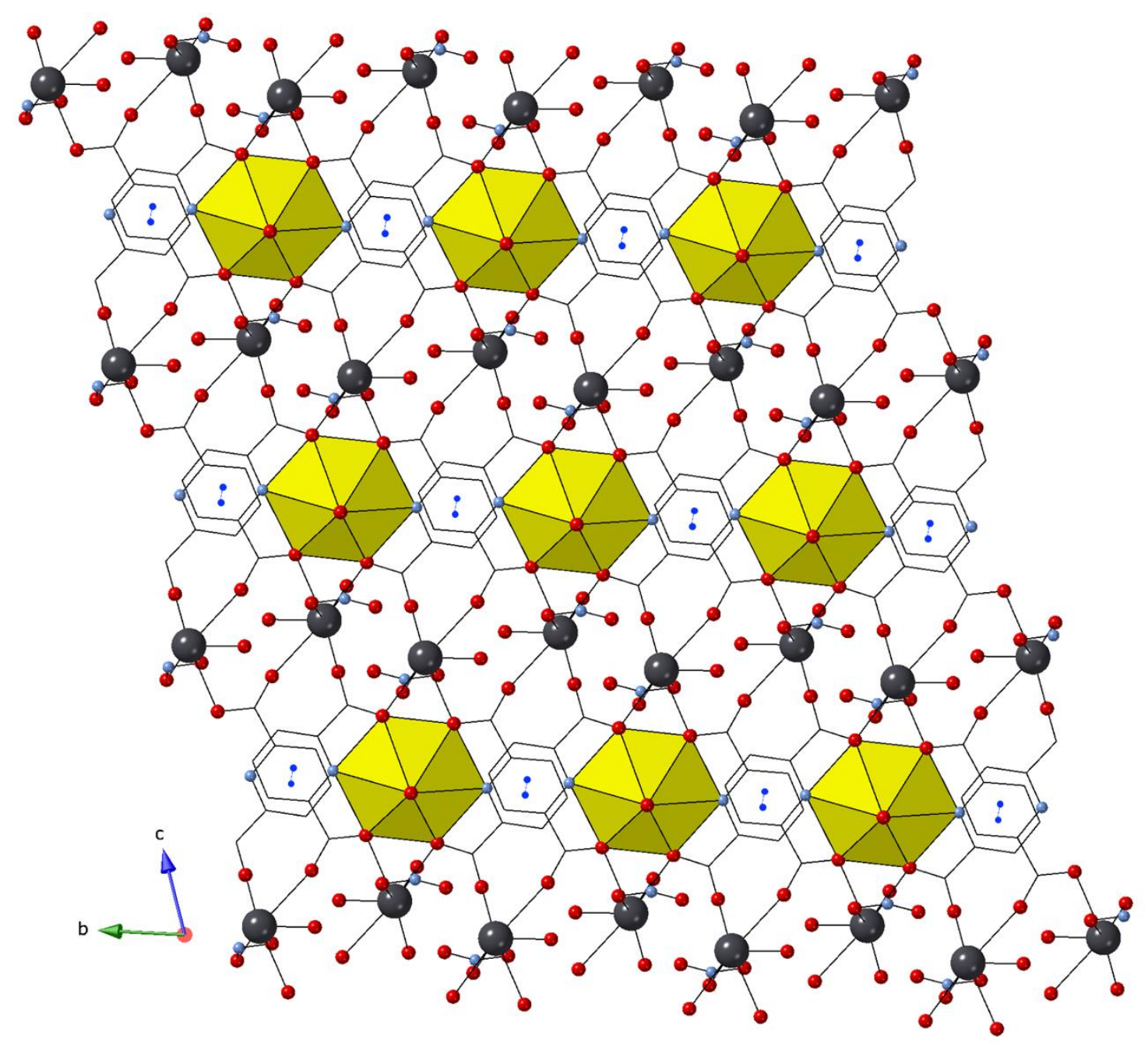

Figure 8. Global structure of compound 4 shown along the $a$-axis. $\pi-\pi$ stacking depicted by blue lines from ring centroids.

Compound 5, $\left[\mathrm{UO}_{2} \mathrm{~Pb}\right.$ (bipy) $(1,2,4,5$-btca $\left.)\right] \cdot 2\left(\mathrm{H}_{2} \mathrm{O}\right)$, crystallizes in the space group $P 2 / n$ and the asymmetric unit contains one crystallographically unique $\mathrm{UO}_{2}{ }^{2+}$ cation adopting a hexagonal bipyramidal geometry and one crystallographically unique 8 -coordinate $\mathrm{Pb}^{2+}$ cation. The $\mathrm{U}=\mathrm{O}$ bonds are symmetry generated and have bond lengths of $1.770(1) \AA$ with a $\angle \mathrm{O}-\mathrm{U}-\mathrm{O}$ of $180(2)^{\circ}$. The $\mathrm{UO}_{2}{ }^{2+}$ cation is coordinated on two sides by bidentate 1,2,4,5-benzentetracarboxylate ligands via $\mathrm{O} 4$ and $\mathrm{O} 5$ and by two monodentate 1,2,4,5-benzenetetracarboxylate ligands via $\mathrm{O} 2$ (Figure 9). The coordination between $\mathrm{UO}_{2}{ }^{2+}$ cations via the 1,2,4,5-benzenetricarboxylate ligands forms 2-dimensional sheets along the $a c$ plane. The uranyl cations are additionally coordinated to $\mathrm{Pb}^{2+}$ cations which form a bidentate coordination via $\mathrm{O} 2$ and $\mathrm{O} 3$ to two 1,2,4,5-benzenetetracarboxylate ligands, linking it to the uranyl cation. The lead also coordinates to two 2,2'-bipyrimidine ligands via $\mathrm{N} 1$ and $\mathrm{N} 2$. These 2,2'-bipyrimidine molecules each coordinate to another $\mathrm{Pb}^{2+}$ cation via the $\mathrm{N} 1$ and $\mathrm{N} 2$ atoms on the other side of the rings. This coordination via the 2,2'-bipyrimidine ligands links the adjacent sheets of uranyl cations, forming a 3-dimensional structure (Figure 10). There 
is no $\mathrm{Pb}$-oxo interaction as the $\mathrm{Pb}^{2+}$ is 4.738 (3) $\AA$ away from the nearest oxo group; the $\angle \mathrm{U}=\mathrm{O}-\mathrm{Pb}$ angle is $76.0(1)^{\circ}$.

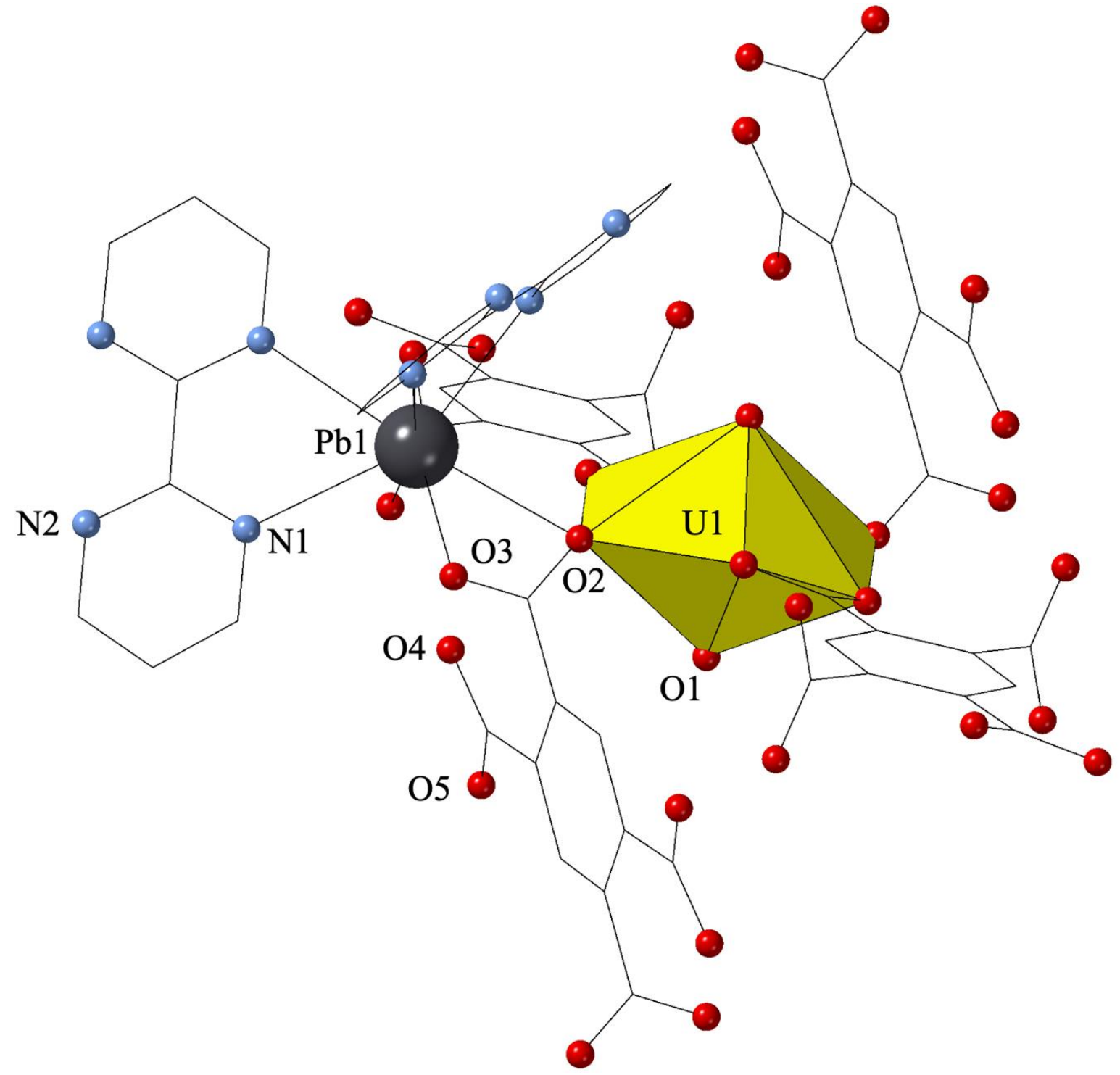

Figure 9. Local representation of compound $\mathbf{5}$ detailing the metal coordination environments. 


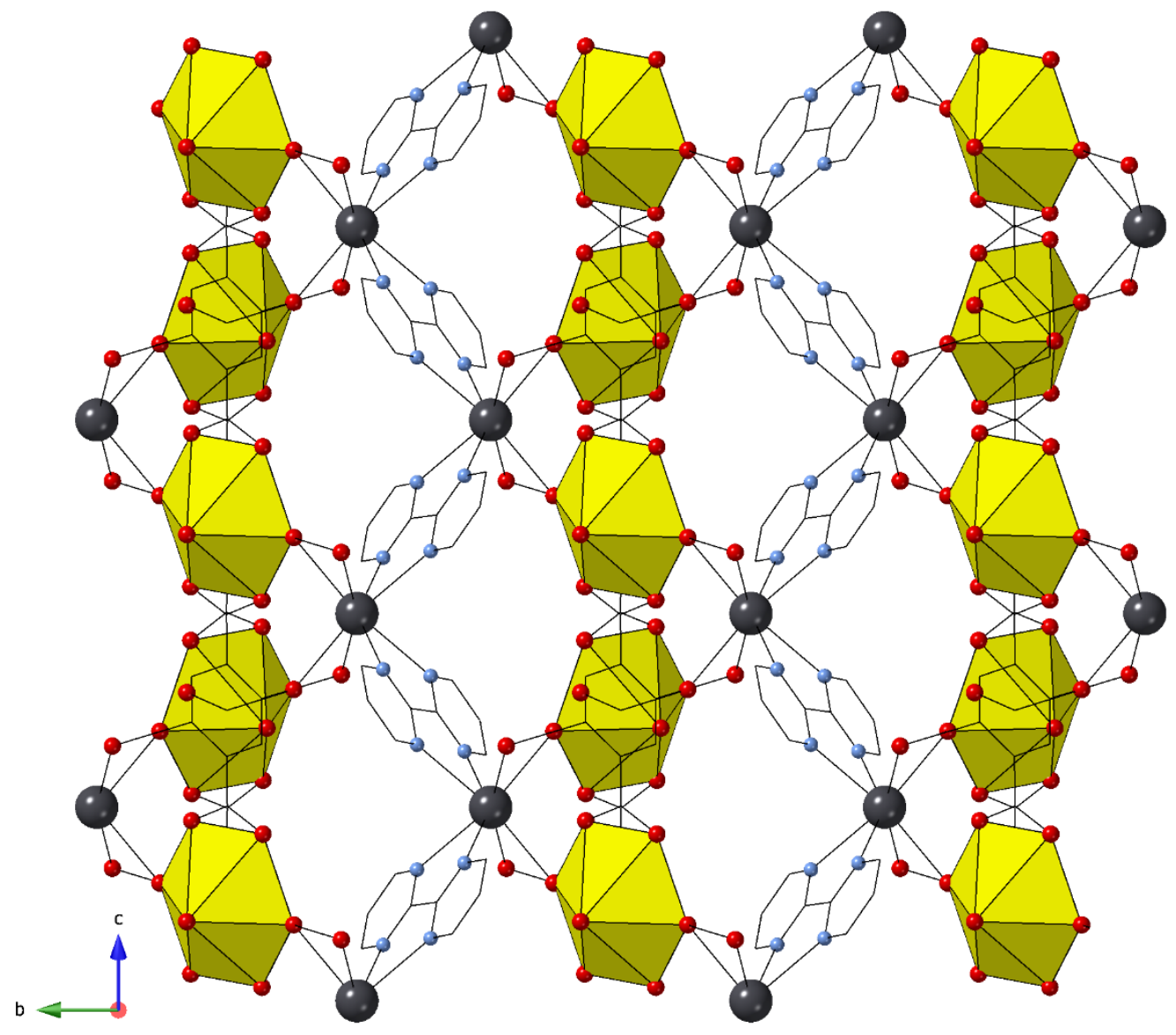

Figure 10. Global structure of compound 5 shown along the $a$-axis.

Compound 6, $\left[\mathrm{UO}_{2} \mathrm{~Pb}(\mathrm{tpy})(1,4-\mathrm{pda})_{4}\right]$, crystallizes in the space group $\mathrm{Pbca}$ the asymmetric unit contains one crystallographically unique $\mathrm{UO}_{2}{ }^{2+}$ cation adopting a hexagonal bipyramidal geometry and a single crystallographically unique 7-coordinate $\mathrm{Pb}^{2+}$ cation. The axial $\mathrm{U}=\mathrm{O}$ bonds have bond lengths of $1.774(2) \AA(\mathrm{O} 1)$ and $1.773(2) \AA(\mathrm{O} 2)$ with a $\angle \mathrm{O}-\mathrm{U}-\mathrm{O}$ of $174.4(1)^{\circ}$. The $\mathrm{UO}_{2}{ }^{2+}$ cation is coordinated to three bidentate 1,4-phenylenediacetate ligands in the equatorial plane (Figure 11). Two of these ligands coordinate via the carboxylate group on the other side of the ring to another uranyl cation whereas the third one forms a bidentate coordination to $\mathrm{a}^{2+}$ cation. Each $\mathrm{Pb}^{2+}$ cation features a bidentate coordination to a 1,4-phenylenediacetate and a mono-dentate to another 1,4-phenylenediacetate carboxylate group which is coordinated to a $\mathrm{UO}_{2}{ }^{2+}$ cation via $\mathrm{O}$. $\mathrm{The}^{\mathrm{Pb}} \mathrm{P}^{2+}$ cation is also capped on one side by a tridentate coordination to a terpyridine ligand. The coordination of the $\mathrm{UO}_{2}{ }^{2+}$ cation to the $\mathrm{Pb}^{2+}$ cations through the 1,4-phenylenediacetate ligands forms 1-dimensional zigzagging chains along (001) which assemble via weak $\mathrm{C}$ - $\mathrm{H}$ hydrogen bonding (Figure 12). There is no Pb-oxo interaction as the $\mathrm{Pb}^{2+}$ is $4.886(2) \AA$ away from the nearest oxo group; the $\angle \mathrm{U}=\mathrm{O}-\mathrm{Pb}$ angle is $70.6(7)^{\circ}$. 


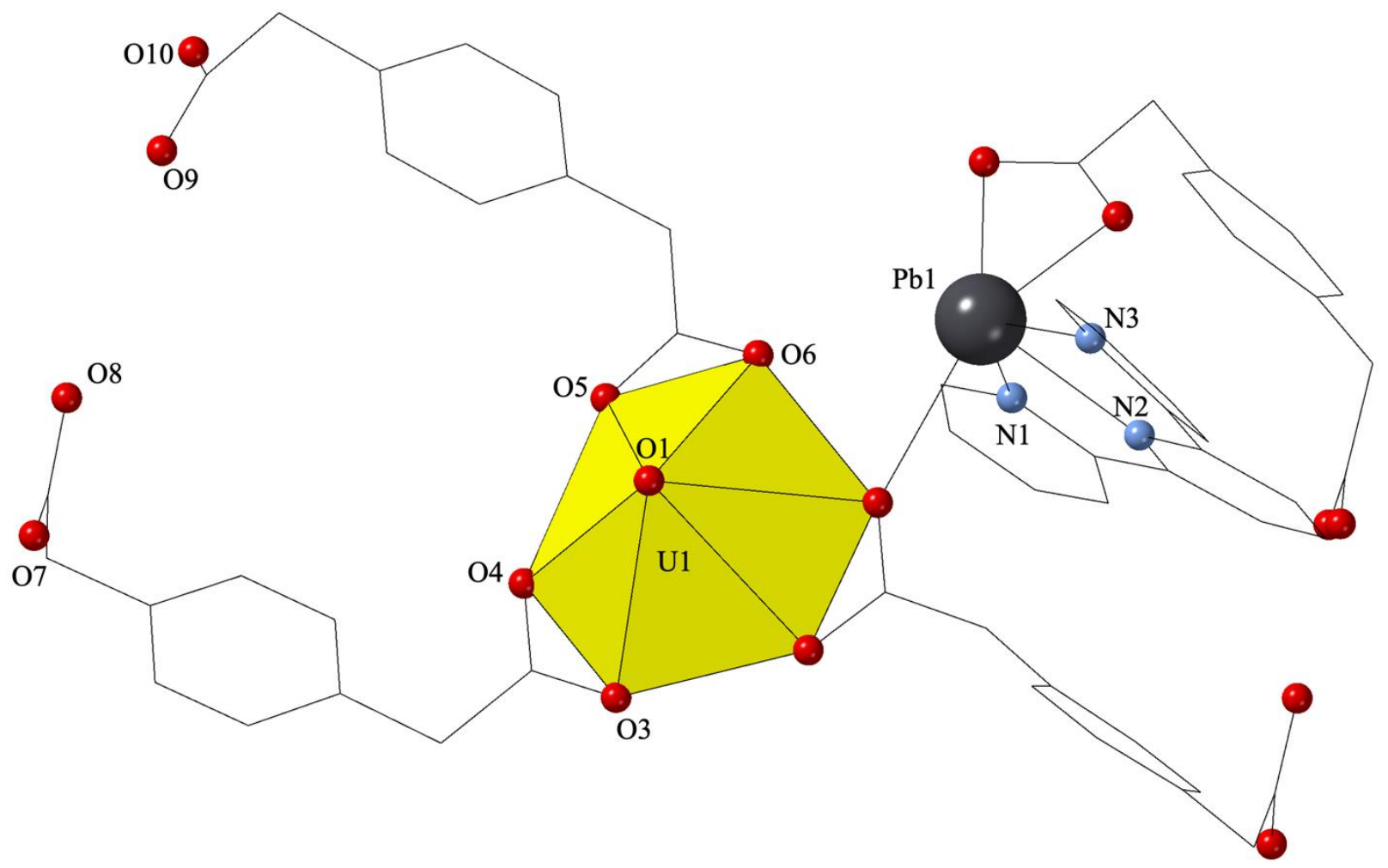

Figure 11. Local representation of compound $\mathbf{6}$ detailing the metal coordination environments.

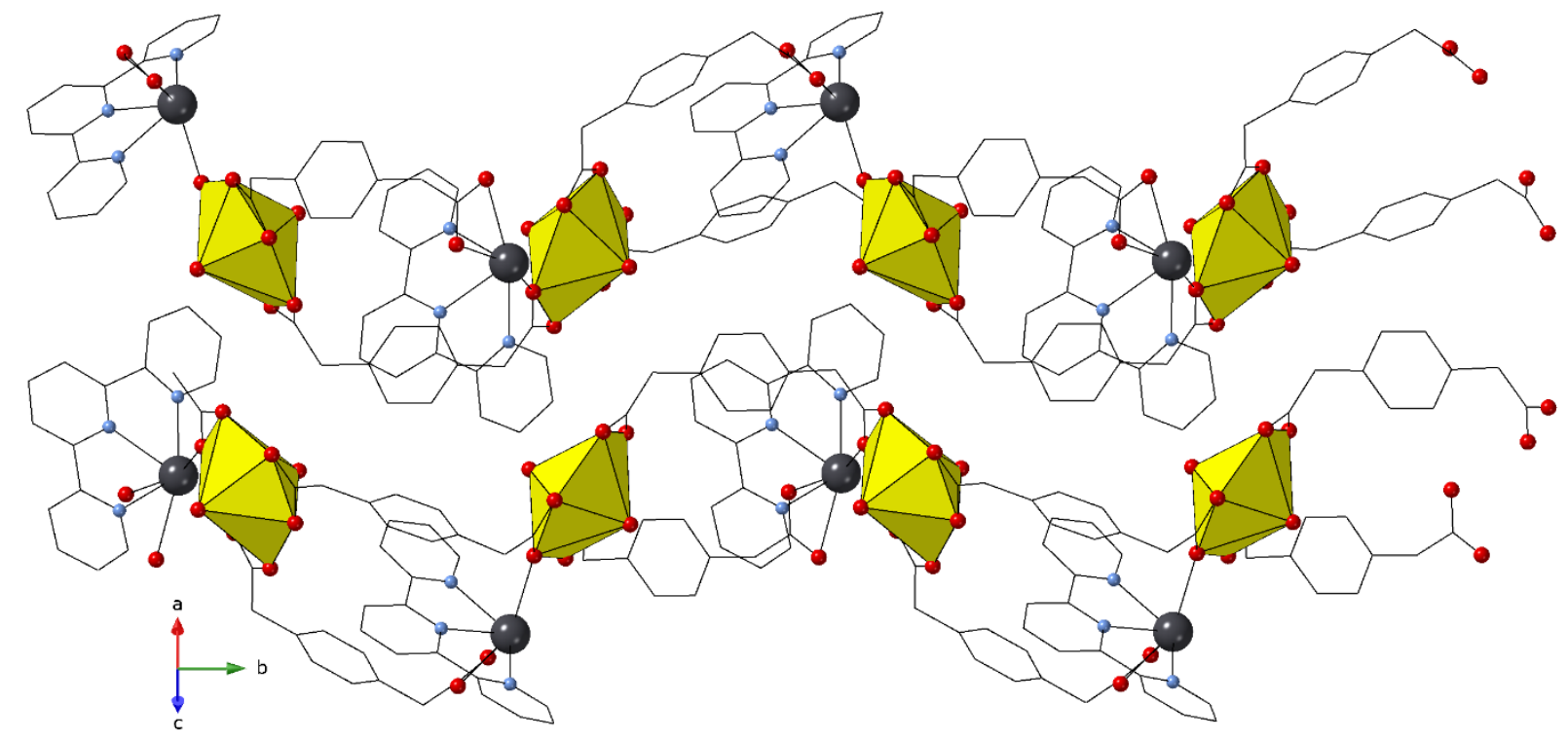

Figure 12. Global structure of compound 6.

$\mathrm{Pb}$ Coordination Sphere and Interactions with Uranyl Oxo atoms. The range of $\mathrm{Pb}-\mathrm{oxo}$ distances within this family of heterometallic compounds provides a suitable platform to study how such interactions with a closed-shell transition metal $\left(\mathrm{Pb}^{2+}\right)$ affects the chemical and optical properties of the uranyl cation. We have tabulated the crystallographic $\mathrm{Pb}$-oxo distances and $\mathrm{U}=\mathrm{O}$ $\mathrm{Pb}$ angles of all of these compounds (Table 3), and these range from 2.816(2) $\AA$ (1) to 4.886(2) $\AA$ 
(6) with $\angle \mathrm{U}=\mathrm{O}-\mathrm{Pb}$ angles between $70.6(7)^{\circ}$ and $150.2(1)^{\circ}$. These parameters are consistent with $\mathrm{Pb}$-oxo distances in reported heterometallic complexes which range between $2.531 \AA$ and $5.429 \AA$ (as determined from a CSD search, vide supra). Within 1-6, we note two subgroups: those with $\mathrm{Pb}$-oxo distances less than or greater than the sum of the van der Waals (vdW) radii $(3.54 \AA) .{ }^{53}$ The vdW radius can serve as a crystallographic metric of the relative strength of the interaction between the $\mathrm{Pb}^{2+}$ and uranyl oxo groups, and we expect those with short $\mathrm{Pb}$-oxo distances (<vdW) to have strong interactions between ion pairs, whereas those outside the vdW to have minimal or no interaction. Compounds 1-3 display short $\mathrm{Pb}$-oxo distances at $<87 \%$ of the vdW radii whereas compounds 4-6 have longer distances that are $>126 \%$ the vdW radii. Close $\mathrm{Pb}$-oxo contacts, as seen in 1-3 have been described in previous work as uranyl-cation interactions and have been observed to cause $\mathrm{U}=\mathrm{O}$ bond asymmetry. ${ }^{12,14,17}$ The $\mathrm{U}=\mathrm{O}$ bond asymmetry reported in $\mathbf{1 - 3}$ is very small, as would be expected in a weaker Lewis acid such as $\mathrm{Pb}^{2+}$, but we do observe bond asymmetry values ca. 0.01-0.02 $\AA$ whereas 4-6 do not display any significant bond asymmetry.

Proximity is not the only factor that can affect the $\mathrm{Pb}$-oxo interaction and we must consider the influence of angles when describing these interactions. Compound $\mathbf{1}$ has a shorter Pb-oxo distance as compared to $\mathbf{2}$, yet the latter displays a higher degree of bond asymmetry. We see that 1-3 have large $\angle \mathrm{U}=\mathrm{O}-\mathrm{Pb}$ angles ranging between $117.2(2)^{\circ}$ to $150.2(1)^{\circ}$. The smaller angle of 2 (vs 1 and 3) suggests that a more side-on approach from the $\mathrm{Pb}^{2+}$ may lead to a more significant M-oxo interaction.

Table 3. Summary of crystallographically determined $\mathrm{Pb}$-oxo interaction parameters.

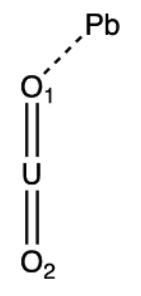

\begin{tabular}{llllll}
\hline Compound & $\mathrm{Pb} \cdots \mathrm{O}_{1}$ & $\% \mathrm{vdW}$ & $\mathrm{Pb} \cdots \mathrm{O}_{1}=\mathrm{U}$ & $\mathrm{U}=\mathrm{O}_{1}$ & $\mathrm{U}=\mathrm{O}_{2}$ \\
\hline $\mathbf{1}$ & $2.816(2) \AA$ & $80 \%$ & $150.2(1)^{\circ}$ & $1.779(3) \AA$ & $1.773(3) \AA$ \\
$\mathbf{2}$ & $2.877(5) \AA$ & $81 \%$ & $117.2(2)^{\circ}$ & $1.789(6) \AA$ & $1.769(6) \AA$ \\
$\mathbf{3}$ & $3.087(3) \AA$ & $87 \%$ & $140.0(1)^{\circ}$ & $1.779(3) \AA$ & $1.770(3) \AA$ \\
$\mathbf{4}$ & $4.467(4) \AA$ & $126 \%$ & $71.9(1)^{\circ}$ & $1.756(1) \AA$ & $1.756(1) \AA$ \\
$\mathbf{5}$ & $4.738(3) \AA$ & $134 \%$ & $76.0(1)^{\circ}$ & $1.770(1) \AA$ & $1.770(1) \AA$ \\
$\mathbf{6}$ & $4.886(2) \AA$ & $138 \%$ & $70.6(7)^{\circ}$ & $1.774(2) \AA$ & $1.773(2) \AA$ \\
\hline
\end{tabular}

\section{Spectroscopic Properties.}


Optical Properties. Interactions (both equatorial and axial) with the $\mathrm{UO}_{2}{ }^{2+}$ cation and subsequent changes to $\mathrm{U}=\mathrm{O}$ bonding often lead to changes in the spectroscopic signatures of uranyl-containing compounds. . $^{8,9,12,14,35,54-56}$ To probe the effects of the close M-oxo interactions in our compounds, we measured the optical properties of 1-6 via diffuse reflectance and luminescence spectroscopy to see if we could note any changes in their optical properties.

As shown in Figure 14, all compounds (less so in 5) display characteristic absorption for uranylcontaining complexes with a band centered around $430 \mathrm{~nm}$ and another centered around $320 \mathrm{~nm}$. These bands correspond to ligand-to-metal charge transfer by the axial oxo groups and equatorial ligands, respectively. The axial band also exhibits splitting of the vibrational peaks owing to strong vibrational coupling with the equatorial ligands. We note in $\mathbf{5}$ a red-shifting of the absorption edge and some loss of the vibrational structure. Compound $\mathbf{4}$ displays strong emission centered at 513 $\mathrm{nm}$ in the diffuse reflectance spectrum (DRS), often seen in uranyl complexes. Despite the difference in Pb-oxo interactions we note no major differences in the DRS of 1-6.

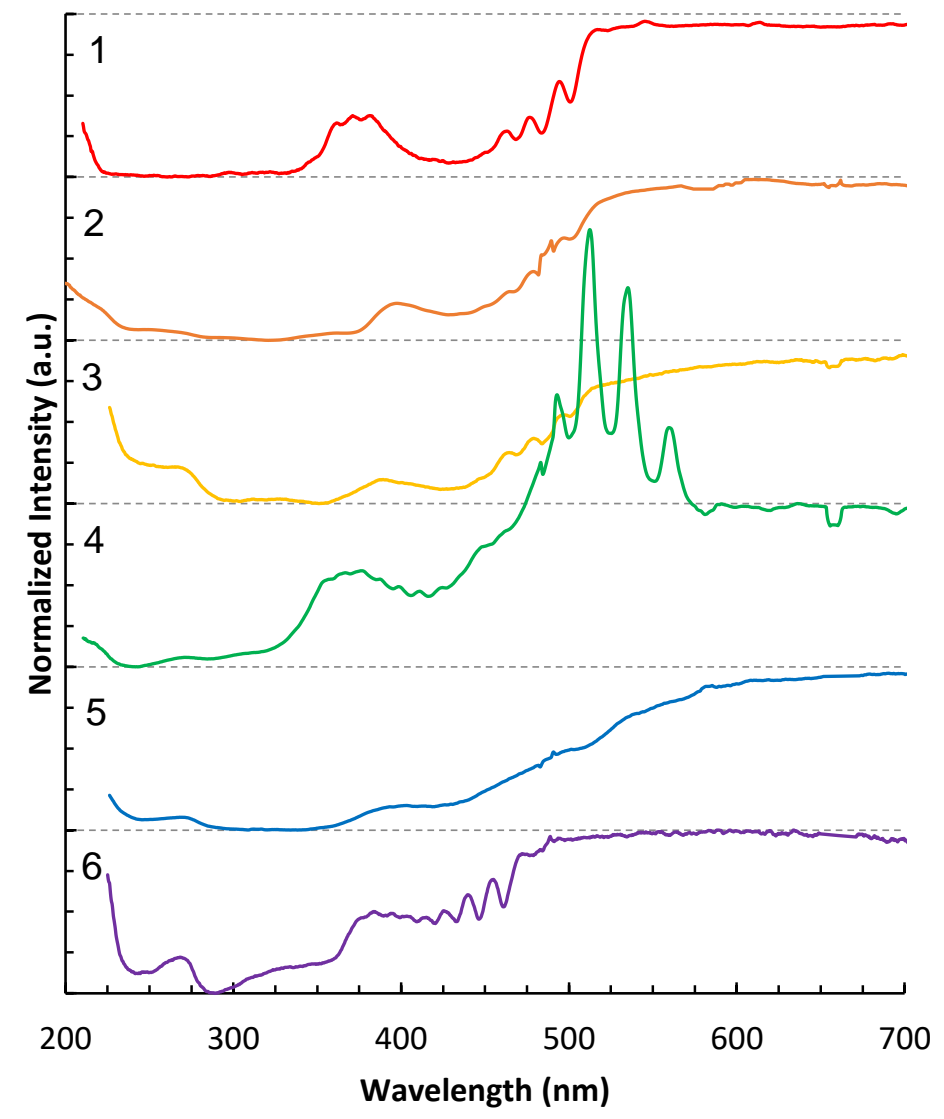

Figure 14. Diffuse reflectance spectra for 1-6 at $298 \mathrm{~K}$.

Uranyl luminescence typically features an emission band ranging from $450 \mathrm{~nm}$ to $650 \mathrm{~nm}$ with finger-like peaks and an excitation profile featuring two bands centered at $420 \mathrm{~nm}$ and $340 \mathrm{~nm}$. The unique uranyl emission profile is due to the electronic transition between non-bonding uranium $5 \mathrm{f} \delta_{\mathrm{u}}$ and $\phi_{\mathrm{u}}$ orbitals and the ground state uranyl bonding orbitals $\left(3 \sigma_{\mathrm{u}}, 3 \sigma_{\mathrm{g}}, 1 \pi_{\mathrm{g}}, 2 \pi_{\mathrm{u}}\right)$ 
coupled with vibrionic resolution corresponding to the $\mathrm{U}=\mathrm{O}$ symmetric stretch, generally around $855 \mathrm{~cm}^{-1} \cdot{ }^{57}$ Compounds 1-6 each display characteristic finger-like uranyl emission (Figure 15) where $\mathbf{1}$ and $\mathbf{4}$ feature additional splitting in the vibrational peaks (seen as shoulders) owing to additional vibrational coupling with the equatorial ligands. Emission spectra display varying degrees of red-shifting with compounds $\mathbf{1}$ and $\mathbf{4}$ centered at $\sim 510 \mathrm{~nm}$ as compared to 3 and $\mathbf{6}$ which are centered at $\sim 500 \mathrm{~nm}$. Compounds $\mathbf{1 - 3}$ display significantly less emission intensity compared to 4-6, consistent with reports of quenching in other complexes with close M-oxo interactions. ${ }^{19-24}$ Based on these results it is clear that the close M-oxo interactions in 1-3 alter the $\mathrm{U}=\mathrm{O}$ bond and subsequently disrupt the luminescence emission pathway leading to non-radiative emission.

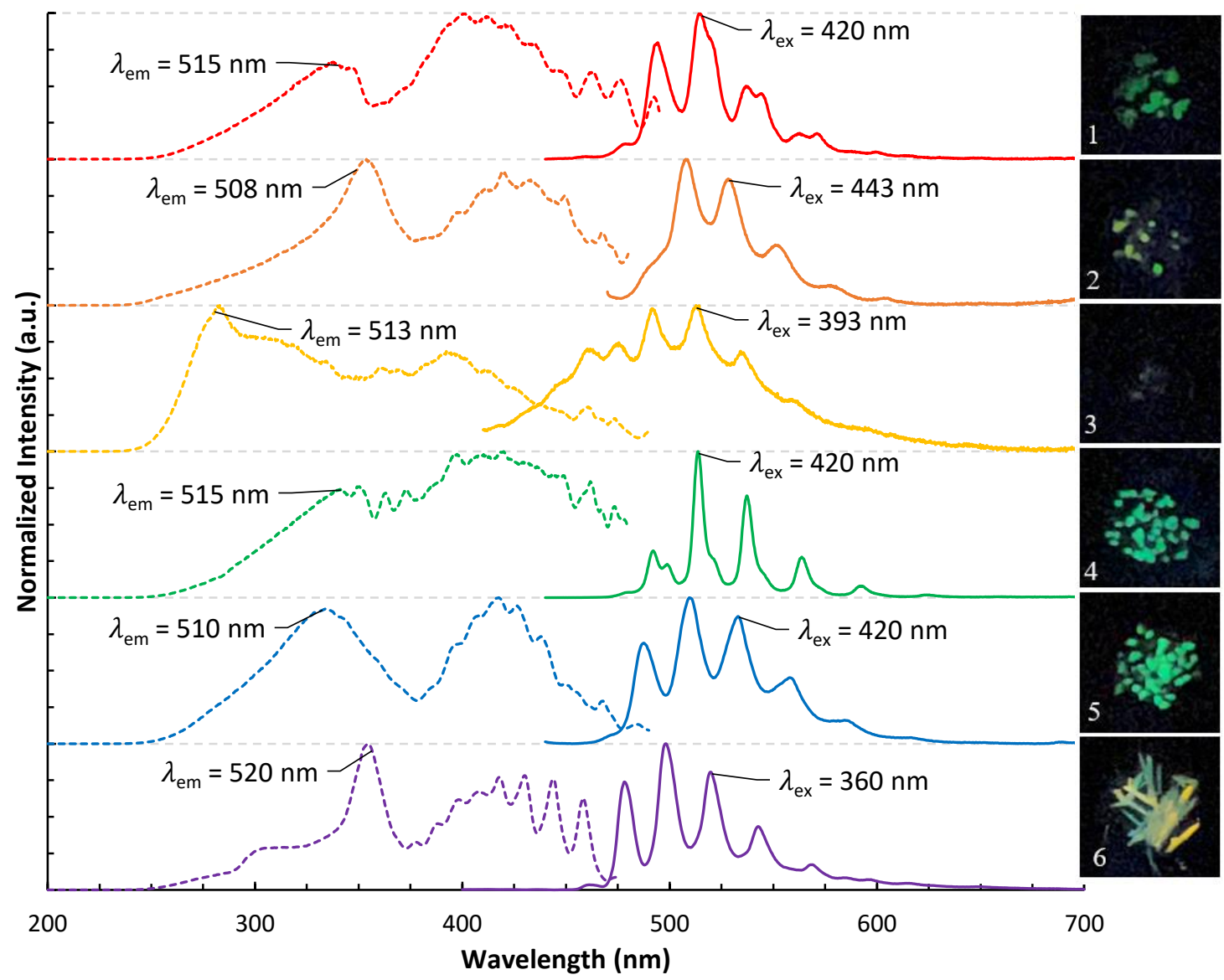

Figure 15. Luminescence spectra of compounds 1-6 at $298 \mathrm{~K}$ with photoimages under a $340 \mathrm{~nm}$ UV light.

Raman spectroscopy. The uranyl cation features three characteristic vibrational modes: a symmetric stretch ( $v_{1}$, Raman active), an asymmetric bend ( $v_{2}$, IR active), and an asymmetric stretch ( $v_{3}$, IR active). The symmetric stretching mode has historically been utilized for identification and classification of uranyl complexes owing to its sensitivity to changes in the coordination environment of the uranyl cation. Values for the symmetric stretch can range from $900 \mathrm{~cm}^{-1}$ to $750 \mathrm{~cm}^{-1}$ but are more typically observed in the $860-880 \mathrm{~cm}^{-1}$ region. ${ }^{35}$ 
The Raman spectra for 1-6 are reported in Figure 16. All compounds except $\mathbf{2}$ exhibit characteristic $\mathrm{U}=\mathrm{O}$ Raman stretch peaks. The values of these peaks for compounds $\mathbf{1}$ and 3-6 are $829 \mathrm{~cm}^{-1}, 812 \mathrm{~cm}^{-1}, 867 \mathrm{~cm}^{-1}, 860 \mathrm{~cm}^{-1}$, and $842 \mathrm{~cm}^{-1}$ respectively. We observe that the values of the peaks for $\mathbf{1}$ and $\mathbf{3}$ are red-shifted in comparison to 4-6. This is consistent with previous work done by our group and others that reported close interaction of a closed-shell transition metal at the uranyl-oxo leading to red-shifting in the $\mathrm{U}=\mathrm{O}$ symmetric stretch peaks. ${ }^{14,58-60}$ Smaller shifts in 4-6 can be attributed to differences in equatorial bonding which has also been shown to affect the position of the $\mathrm{U}=\mathrm{O}$ symmetric stretch. ${ }^{35,60}$

For 2, no uranyl peak is observed and only those assigned to $2,2^{\prime} ; 6^{\prime}, 2^{\prime \prime}$-terpyridine are present. ${ }^{61}$ To explain the curious loss of the $\mathrm{U}=\mathrm{O}$ symmetric stretch, a series of DFT calculations were performed (see SI) where the interaction between the axial and equatorial ligands were varied. Modelling results found that in cases containing simultaneous axial and equatorial interactions, the $\mathrm{U}=\mathrm{O}$ Raman signature is significantly suppressed. Such is the case with compound $\mathbf{2}$ which features a short $\mathrm{Pb}$-oxo distance of 2.877(5) $\AA$ and a Pb-O eq distance of 2.990(5) $\AA$, both within the vdW at $81 \%$ and $85 \%$, respectively. Strong interaction with both the axial and equatorial ligands is therefore most likely responsible for the loss of the $\mathrm{U}=\mathrm{O}$ Raman stretch. The red-shifting in the Raman seen in compounds $\mathbf{1}$ and $\mathbf{3}$ is consistent with the bond length asymmetry observed in the crystallographic data (albeit subtle).

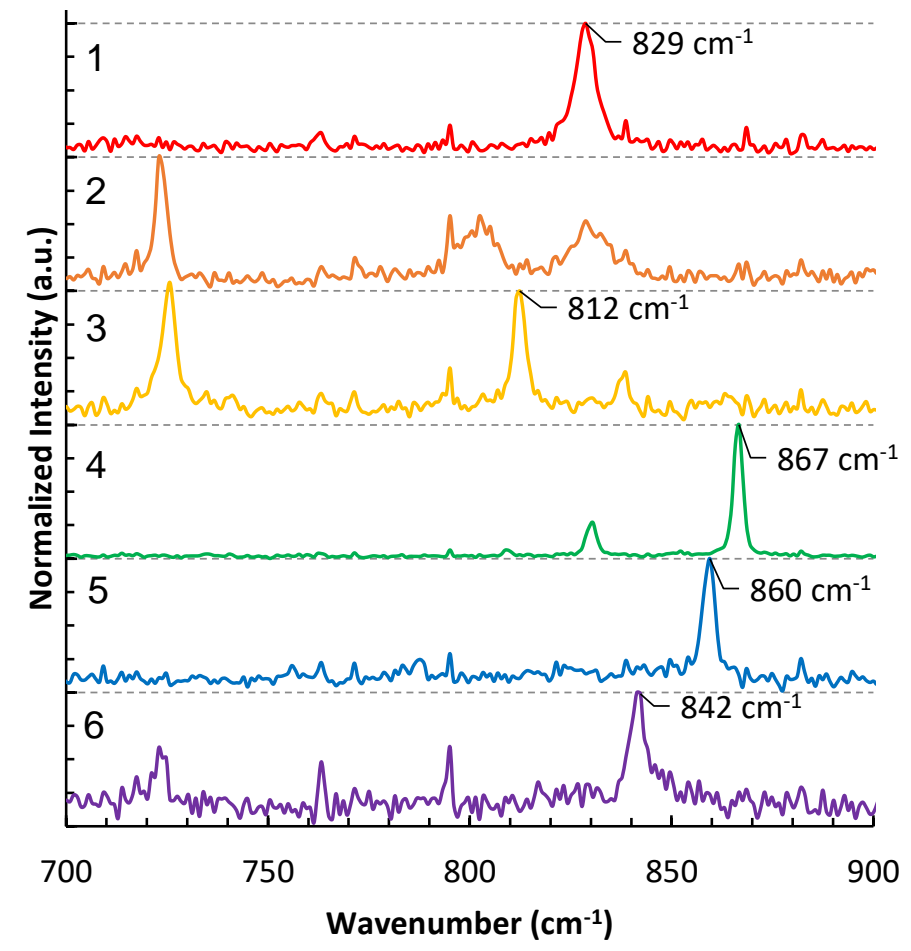

Figure 16. Raman spectra of compounds 1-6 at $298 \mathrm{~K}$.

\section{Characterizing Uranyl Second Sphere Interactions and Inner Sphere Bonding}


Second Sphere Interactions. In an effort to probe the second-sphere interaction between the $\mathrm{Pb}^{2+}$ and uranyl-oxo groups for the complexes reported herein, we performed second order perturbation theory (SOPT) based NBO calculations in order to determine the orbitals involved in the interactions. These calculations provide two important descriptions of the uranyl-cation interactions: (i) determination of molecular orbitals involved and (ii) quantification of interaction strength in $\mathrm{kcal} / \mathrm{mol}$. Calculations were carried out on 1-6 as well as on a collection of 10 additional heterometallic $\mathrm{UO}_{2}{ }^{2+} / \mathrm{Pb}^{2+}$ structures by Thuery et al. which provided a larger dataset in order to develop a more general understanding. ${ }^{19-22,24}$ The complexes reported herein have $\mathrm{Pb}$-oxo distances in two groups with 1-3 falling within the vdW radius and 4-6 falling well outside the $\mathrm{vdW}$ radius. The distances of these two groups fall at the extremes of the reported range, yet those reported by Thuery provide a greater sample size and thus more continuity in interaction distances.

We first identified the atomic and/or molecular orbitals involved in interactions between $\mathrm{Pb}^{2+}$ and $\mathrm{UO}_{2}{ }^{2+}$. Our findings (Figure 17) reveal that the uranyl-cation interaction in each compound can be broken down into four types of orbital interactions as dictated by the identity of the orbital donor/acceptor pairs: (1) electron donor $\mathrm{Pb} s$ lone pair and an acceptor empty $\mathrm{U} 5 f$ orbital, (2) a donor $\mathrm{Pb} s$ lone pair and a $\mathrm{UO}_{2} \sigma^{*}$ antibonding orbital acceptor, (3) a donor $\mathrm{O} s p^{x}$ lone pair and an acceptor $\mathrm{Pb} p$ orbital, and (4) a donor $\mathrm{UO}_{2} \sigma$ bonding orbital and an empty acceptor $\mathrm{Pb} p$ orbital. The Type 2 and Type 4 interactions are of particular note as they involve the bonding-relevant $\mathrm{U}=\mathrm{O} \sigma$ and $\mathrm{U}=\mathrm{O} \sigma^{*}$ orbitals, suggesting that interactions involving strong $\mathrm{U}=\mathrm{O} \sigma$ charge donor and/or $\mathrm{U}=\mathrm{O} \sigma^{*}$ charge acceptor behavior would lead to weakening of the $\mathrm{U}=\mathrm{O}$ bond.

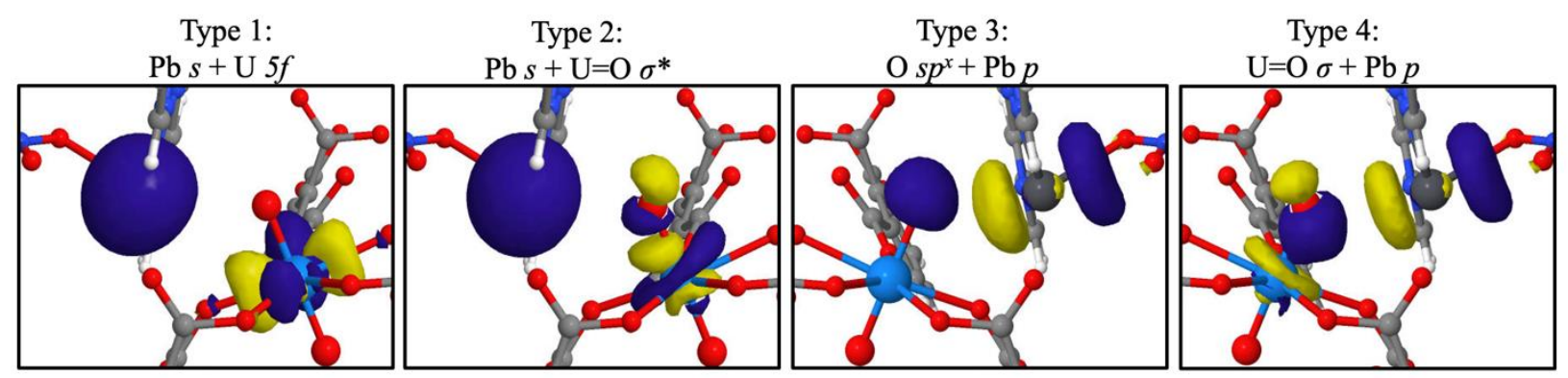

Figure 17. Isodensity renderings of representative orbitals involved in $\mathrm{Pb}$-oxo interactions using compound 2 as a model.

The stabilization energies for the orbital pairs found in 1-6, along with $\mathrm{Pb}$-oxo distances, are tabulated in Table 4. Subsequent stabilization energies for compounds reported by Thuery et al can be found in Table S8 in the SI. The Type 3 interactions in these compounds consistently dominate, generally making up 50\% of the overall interaction strength. The strength of these interactions varies greatly depending on how closely the $\mathrm{Pb}^{2+}$ interacts with the oxo, with values greater than $8 \mathrm{kcal} / \mathrm{mol}$ in $\mathbf{1 - 3}$ (whose distances fall within the sum of the vdW radius) and values less than $2 \mathrm{kcal} / \mathrm{mol}$ in 4-6 (whose distances fall outside the sum of the vdW radius). The Type 1 and Type 2 interactions are usually much weaker, indicating poor charge acceptor behavior from the $\mathrm{UO}_{2}{ }^{2+}$ cation. Type 4 interactions are weaker as well, although their values are generally larger than the Type 1 and Type 2 interactions for the closer $\mathrm{Pb}$-oxo interactions (compounds 1-3) and 
smaller for the complexes with virtually no $\mathrm{Pb}$-oxo interactions (compounds 4-6). The Type 2 and Type 4 bonding-relevant interactions make up a smaller part of the overall interaction between the lead and the uranyl unit which could explain why the bond-length asymmetry observed in 1-3 in the crystallographic data is small. Additionally, the $\mathrm{U}=\mathrm{O}$ bonding orbitals described in this interaction play a role in the emission pathway for uranyl luminescence and strong interactions with these orbitals could lead to a change in the luminescence pathway which would lead to nonradiative emission.

Table 4. Second Order Perturbation Theory calculated NCI stabilization energies ( $\left.\mathrm{kcal} \mathrm{mol}^{-1}\right)$ and orbitals involved in charge transfer.

\begin{tabular}{|c|c|c|c|c|c|c|}
\hline & \multicolumn{3}{|c|}{$\mathbf{P b}^{2+} \rightarrow \mathrm{UO}_{2}{ }^{2+}$} & \multicolumn{2}{|c|}{$\mathbf{U O}_{2}{ }^{2+} \rightarrow \mathbf{P b}^{2+}$} & \multirow[b]{2}{*}{$\begin{array}{c}\text { Total } \\
(\mathbf{k c a l} / \mathbf{m o l})\end{array}$} \\
\hline & $\begin{array}{c}\text { Pb-O } \\
\text { Distance }\end{array}$ & $\begin{array}{c}\text { Type } 1 \\
\mathrm{~Pb} \mathrm{~s} \rightarrow \text { U5f } \\
(\mathrm{kcal} / \mathrm{mol})\end{array}$ & $\begin{array}{c}\text { Type } 2 \\
\mathrm{~Pb} \mathrm{~s} \rightarrow \mathrm{UO}_{2} \sigma^{*} \\
(\mathrm{kcal} / \mathrm{mol})\end{array}$ & $\begin{array}{c}\text { Type } 3 \\
\mathrm{O} \mathrm{sp}^{\mathrm{x}} \rightarrow \mathrm{Pb} \text { p } \\
(\mathrm{kcal} / \mathrm{mol})\end{array}$ & $\begin{array}{c}\text { Type } 4 \\
\mathrm{UO}_{2} \sigma \rightarrow \mathrm{Pb} p \\
(\mathrm{kcal} / \mathrm{mol})\end{array}$ & \\
\hline 1 & $2.812 \AA$ & 0.05 & 1.84 & 12.89 & 2.27 & 17.05 \\
\hline 2 & $2.882 \AA$ & 2.31 & 0.60 & 16.92 & 2.11 & 21.94 \\
\hline 3 & $3.089 \AA$ & 0.00 & 0.94 & 8.34 & 1.43 & 10.71 \\
\hline 4 & $4.476 \AA$ & 0.41 & 0.17 & 1.46 & 0.38 & 2.42 \\
\hline 5 & $4.752 \AA$ & 0.15 & 0.00 & 0.26 & 0.06 & 0.47 \\
\hline 6 & $4.886 \AA$ & 0.34 & 0.22 & 0.51 & 0.17 & 1.24 \\
\hline
\end{tabular}

By combining the individual stabilization energies of each of the four orbital interaction types listed above, we can determine the overall stabilization energy of the interaction between the metal and the uranyl unit. Plotting the combined stabilization energies of all four types vs Pb-oxo distance (Figure 18) we find that the interaction strength increases exponentially with M-oxo distance. Compound 2, with the largest stabilization energy $(21.94 \mathrm{kcal} / \mathrm{mol})$, corresponds to a $\mathrm{Pb}$ oxo distance of 2.877(5) $\AA$. Compound 5, in contrast, has the smallest stabilization energy (0.47 $\mathrm{kcal} / \mathrm{mol}$ ), corresponding to a distance of 4.738(3) $\AA$. Within these overall trends we note that while compound $\mathbf{1}$ has the closest $\mathrm{Pb}$-oxo distance, compound $\mathbf{2}$ has a much higher stabilization energy. This is mirrored by the larger bond asymmetry observed in the crystallographic data of 2 as compared to $\mathbf{1}$. We once again posit that the angle of $\mathrm{Pb}$-oxo interaction likely plays a role in the larger effect of the $\mathrm{Pb}$ in 2 . Compound 2 has a much smaller angle of interaction $\left(117.2^{\circ}\right)$ as compared with 1 and $3\left(150.2^{\circ}\right.$ and $\left.140.0^{\circ}\right)$ with the $\mathrm{Pb}^{2+}$ approaching the uranyl from the side rather than closer to the top. This side-on approach could lead to more favorable orbital overlap in 2 leading to a stronger interaction and higher bond asymmetry as compared to 1. While 4-6 do not experience these close $\mathrm{Pb}$-oxo interactions we still note that whereas compound $\mathbf{5}$ has a shorter $\mathrm{Pb}$ oxo distance than 6, it has a much lower interaction strength. This could be due to the larger angle of interaction at $75.8^{\circ}$ as compared to 4 and 6 which have angles of $71.9^{\circ}$ and $70.6^{\circ}$ respectively. This data suggests an ideal angle of approach for stronger $\mathrm{Pb}$-oxo interactions which is likely dictated by favorable orbital overlap as the $\mathrm{Pb}$-oxo distance decreases. 


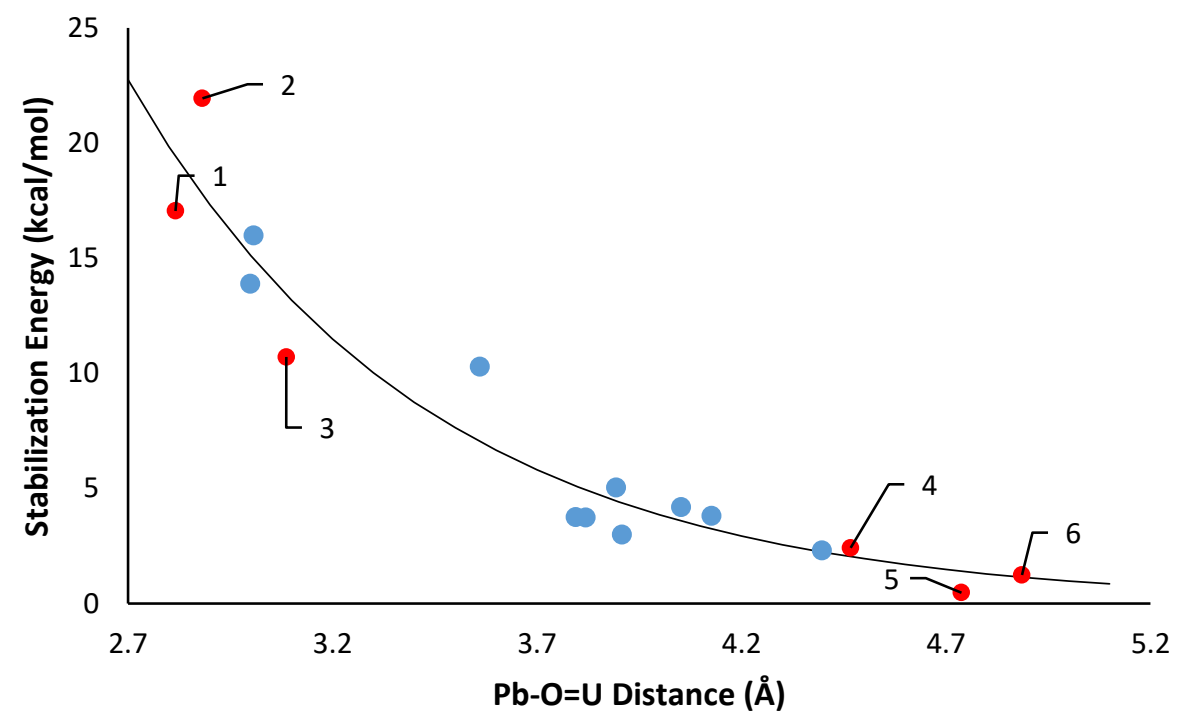

Figure 18. Plot of $\mathrm{Pb}$-oxo distance versus total uranyl-cation interaction stabilization energy highlighting the relationship between distance and interaction strength between the $\mathrm{UO}_{2}{ }^{2+}$ and the $\mathrm{Pb}^{2+}$ units. Red data points correspond to 1-6 in this paper. Blue data points correspond to compounds from Thuery et. al. ${ }^{19-22,24}$

Inner Sphere $U=O$ Bonding. QTAIM determines bond critical points (BCP) between close atom pairs and calculates the electron densities thereof, which are a useful measure of bond strength and covalency; ${ }^{62-64}$ higher BCP electron densities indicate stronger, more covalent bonds. The electron densities $(\rho)$ at the bond critical points for the interaction between the $\mathrm{Pb}^{2+}$ and the uranyl-oxo, as well as the $\mathrm{U}=\mathrm{O}$ bonds in 1-6 are summarized in Table 5. QTAIM results for the compounds reported by Thuery et. al. can be found in Table S9 in the SI. Compounds 1-3 (with Pb-oxo interactions) have $\rho$ values ranging from 0.013 to 0.020 . Compounds 4-6 did not have bond critical points calculated between the $\mathrm{Pb}^{2+}$ and the uranyl-oxo owing to the longer $\mathrm{Pb}$-oxo distances and thus no appreciable interactions.

The $\mathrm{BCPs}$ for $\mathrm{U}=\mathrm{O}$ bonds (with $\mathrm{Pb}^{2+}$ interactions) in $\mathbf{1 - 3}$ have electron density values of 0.298 for $\mathbf{1}$ and $\mathbf{3}$ and 0.289 for $\mathbf{2}$. These values are lower than the terminal $\mathrm{U}=\mathrm{O}$ bonds in $\mathbf{1 - 3}(\rho=0.304$, 0.307 , and 0.307 respectively) and 4-6 ( $\rho=$ of $0.317,0.311$, and 0.314 respectively) indicating bond weakening and loss of covalent character in compounds with close $\mathrm{Pb}$-oxo interactions. This data is consistent with the subtle bond length asymmetry observed in the crystallographic data. The loss of covalent character in $\mathrm{U}=\mathrm{O}$ bonds occurs due to a buildup of charge on the individual atoms leading to an increased electrostatic repulsion. ${ }^{63}$ Natural population analysis done using NBO however, revealed no trends in the charges on the oxo and uranium atoms, suggesting an influence from equatorial ligands- the nature of which may be quite variable owing to the diversity of ligand types present.

Table 5. Quantum Theory of Atom in Molecules calculated bond critical point electron densities ( $\rho$ ) 


\begin{tabular}{|c|c|c|c|}
\hline & Pb-O & $\mathrm{U}=\mathrm{O}(\mathrm{Pb})$ & $\mathbf{U}=\mathbf{O}$ \\
\hline 1 & 0.020 & 0.298 & 0.304 \\
\hline 2 & 0.020 & 0.289 & 0.307 \\
\hline 3 & 0.013 & 0.298 & 0.307 \\
\hline 4 & 0.000 & 0.317 & 0.314 \\
\hline 5 & 0.000 & 0.311 & 0.313 \\
\hline 6 & 0.000 & 0.314 & 0.320 \\
\hline
\end{tabular}

These results are supported by our predictions made based on the SOPT data. The aforementioned population of the antibonding orbital and the depopulation of the bonding orbital in the Type 2 and Type 4 interactions could explain this weakening displayed by the $\mathrm{U}=\mathrm{O}$ bonds as a consequence of their interaction with $\mathrm{Pb}^{2+}$. It is of note that compound 2 , which had the highest stabilization energy, also displayed the highest bond asymmetry in both the crystallographic and the QTAIM data. The difference in electron density values between the $\mathrm{U}=\mathrm{O}$ bonds $\mathrm{Pb}^{2+}$ and those that do not interact is clear, demonstrating that $\mathrm{Pb}$-oxo interaction has a substantial effect on the strength of the uranyl bond. The effects of this weakening in the uranyl bond is supported experimentally by the red-shifting displayed in the $\mathrm{U}=\mathrm{O}$ symmetric stretch in the Raman spectra of $\mathbf{1}$ and $\mathbf{3}$ and the quenching of the uranyl luminescence in 1-3 which demonstrates perturbation of the $\mathrm{U}=\mathrm{O}$ bond.

\section{Conclusion}

The syntheses and characterization of six novel uranyl/lead heterometallic complexes have been described. Interactions between the $\mathrm{Pb}^{2+}$ and the uranyl-oxo groups were characterized structurally, computationally, and spectroscopically. Structural determination revealed close uranyl-cation interactions between the $\mathrm{Pb}^{2+}$ and the uranyl-oxo in compounds $\mathbf{1 - 3}$ fall within $87 \%$ of the van der Waals radii for those atoms. Computational data demonstrated that as the Pb-oxo distance decreases, the interactions energy as determined by SOPT increases exponentially. These energies range from $21.94 \mathrm{kcal} / \mathrm{mol}$ to $0.47 \mathrm{kcal} / \mathrm{mol}$ and arise primarily from the charge transfer from donor $\mathrm{O} s p^{x}$ and acceptor $\mathrm{Pb} p$ atomic orbitals. Notably, the interaction also involves $\mathrm{U}=\mathrm{O} \sigma$ and $\sigma^{*}$ molecular orbitals which may act as charge donors or acceptors, respectively. Exploration of inner sphere bonding via QTAIM demonstrates that strong interactions lead to an asymmetric weakening of the $\mathrm{U}=\mathrm{O}$ bonds and a loss of covalent character as observed as red-shifting of the $\mathrm{U}=\mathrm{O}$ symmetric stretch in the Raman. Additionally, in cases of strong Pb-oxo interactions the typical uranyl luminescence is quenched likely as a result of disruption of the uranyl bonding leading to a change in the emission pathway. This work not only represents a substantial addition to the known examples of heterometallic $\mathrm{Pb}^{2+} / \mathrm{UO}_{2}{ }^{2+}$ materials, but also provides an orbital level description of the influence of closed-shell, post-transition metals on spectroscopic signatures. Future work is in progress to study how other closed-shell transition and post-transition metals such as $\mathrm{Ag}^{+}$could interact with the $\mathrm{UO}_{2}{ }^{2+}$ and the effects of these interactions both structurally and spectroscopically. 


\section{Associated Content}

\section{Electronic Supplementary Information}

The Electronic Supplementary Information is available free of charge on the RSC Publications website. Crystallographic information on CCDC 2064213-2064218 can be obtained free of charge by e-mailing data_request@ccdc. cam.ac.uk or by contacting The Cambridge Crystallographic Data Centre, 12 Union Road, Cambridge, CB2 1EZ UK; Fax +44(0)1223-336033; http://www.ccdc.cam.ac.uk/data_reque st/cif.

Crystallography Tables, PXRD, Luminescence Data at 78K, additional NBO and QTAIM data, DFT models (pdf)

$\mathrm{X}$-ray data for compound $\mathbf{1}(\mathrm{CIF})$

$\mathrm{X}$-ray data for compound $\mathbf{2}(\mathrm{CIF})$

$\mathrm{X}$-ray data for compound $\mathbf{3}(\mathrm{CIF})$

$\mathrm{X}$-ray data for compound $4(\mathrm{CIF})$

$\mathrm{X}$-ray data for compound $\mathbf{5}(\mathrm{CIF})$

$\mathrm{X}$-ray data for compound $\mathbf{6}(\mathrm{CIF})$

\section{Author Information}

*Christopher L. Cahill - Department of Chemistry, The George Washington University, Washington, DC 20052, United States; orcid.org/0000-0002-2015-3595;

Email: cahill@gwu.edu

\section{Authors}

Dominque M. Brager - Department of Chemistry, The George Washington University, Washington, DC 20052, United States; orcid.org/0000-0003-0694-0805;

Email: dbrager@gwu.edu

Aaron D. Nicholas - Pacific Northwest National Laboratory, Washington, DC 20052, United States; orcid.org/0000-0001-9003-2126;

Email: aaron_nicholas@gwu.edu

Mark H. Schofield - Department of Chemistry, The George Washington University, Richland, WA 99354, United States; orcid.org/0000-0002-9601-7186;

Email:mschofie@gwu.edu

\section{Author Contributions}

The manuscript was written with contributions from all authors.

\section{Notes}

The authors declare no competing financial interests. 


\section{Acknowledgment}

This study was supported by the U.S. Department of Energy (DOE) - Chemical Sciences, Geosciences, and Biosciences Division, Office of Science, Office of Basic Energy Sciences, Heavy Elements Program, under grant number DE-FG02-05ER15736. The authors would like to thank Professor Karah Knope and Dr. Nicole Vanagas of Georgetown University for providing Raman microscope time. We would also like to thank Professor Raymond Butcher of Howard University for his help with structural refinement of Compound 2.

\section{References.}

(1) Loiseau, T.; Mihalcea, I.; Henry, N.; Volkringer, C. The Crystal Chemistry of Uranium Carboxylates. Coordination Chemistry Reviews. Elsevier May 1, 2014, pp 69-109. https://doi.org/10.1016/j.ccr.2013.08.038.

(2) Andrews, M. B.; Cahill, C. L. Uranyl Bearing Hybrid Materials: Synthesis, Speciation, and SolidState Structures. Chem. Rev. 2012, 113 (2), 1121-1136. https://doi.org/10.1021/CR300202A.

(3) Cahill, C. L.; Lill, D. T. de; Frisch, M. Homo- and Heterometallic Coordination Polymers from the f Elements. CrystEngComm 2006, 9 (1), 15-26. https://doi.org/10.1039/B615696G.

(4) Cahill, C. L.; De Lill, D. T.; Frisch, M. Homo- and Heterometallic Coordination Polymers from the f Elements. CrystEngComm. Royal Society of Chemistry December 15, 2007, pp 15-26. https://doi.org/10.1039/b615696g.

(5) Wang, K. X.; Chen, J. S. Extended Structures and Physicochemical Properties of Uranyl-Organic Compounds. Acc. Chem. Res. 2011, 44 (7), 531-540. https://doi.org/10.1021/ar200042t.

(6) Yang, W.; Parker, T. G.; Sun, Z. M. Structural Chemistry of Uranium Phosphonates. Coordination Chemistry Reviews. Elsevier November 1, 2015, pp 86-109. https://doi.org/10.1016/j.ccr.2015.05.010.

(7) Jayasinghe, A. S.; Payne, M. K.; Forbes, T. Z. Synthesis and Characterization of Heterometallic Uranyl Pyridinedicarboxylate Compounds. J. Solid State Chem. 2017, 254, $25-31$. https://doi.org/10.1016/j.jssc.2017.07.002.

(8) Carter, K. P.; Kalaj, M.; McNeil, S.; Kerridge, A.; Schofield, M. H.; Ridenour, J. A.; Cahill, C. L. Structural, Spectroscopic, and Computational Evaluations of Cation-Cation and Halogen Bonding Interactions in Heterometallic Uranyl Hybrid Materials. Inorg. Chem. Front. 2021. https://doi.org/10.1039/D0QI01319F.

(9) Arnold, P. L.; Patel, D.; Blake, A. J.; Wilson, C.; Love, J. B. Selective Oxo Functionalization of the Uranyl Ion with 3d Metal Cations. J. Am. Chem. Soc. 2006, 128 (30), 9610-9611. https://doi.org/10.1021/JA0634167.

(10) Arnold, P. L.; Pécharman, A.-F.; Hollis, E.; Yahia, A.; Maron, L.; Parsons, S.; Love, J. B. Uranyl Oxo Activation and Functionalization by Metal Cation Coordination. Nat. Chem. 2010212 2010, 2 (12), 1056-1061. https://doi.org/10.1038/nchem.904.

(11) Arnold, P. L.; Hollis, E.; White, F. J.; Magnani, N.; Caciuffo, R.; Love, J. B. Single-Electron Uranyl Reduction by a Rare-Earth Cation. Angew. Chemie Int. Ed. 2011, 50 (4), 887-890. https://doi.org/10.1002/ANIE.201005511.

(12) Fortier, S.; Hayton, T. W. Oxo Ligand Functionalization in the Uranyl Ion (UO22+). Coord. Chem. Rev. 2010, 254 (3-4), 197-214. https://doi.org/10.1016/J.CCR.2009.06.003.

(13) Savchenkov, A. V.; Vologzhanina, A. V.; Serezhkina, L. B.; Pushkin, D. V.; Stefanovich, S. Y.; Serezhkin, V. N. Synthesis, Structure, and Nonlinear Optical Activity of K, Rb, and Cs Tris(Crotonato)Uranylates(VI). Zeitschrift für Anorg. und Allg. Chemie 2015, 641 (6), 1182-1187. https://doi.org/10.1002/ZAAC.201400575.

(14) Bell, N. L.; Arnold, P. L.; Love, J. B. Controlling Uranyl Oxo Group Interactions to Group 14 
Elements Using Polypyrrolic Schiff-Base Macrocyclic Ligands. Dalt. Trans. 2016, 45 (40), 15902-15909. https://doi.org/10.1039/C6DT01948J.

(15) Volkringer, C.; Henry, N.; Grandjean, S.; Loiseau, T. Uranyl and/or Rare-Earth Mellitates in Extended Organic-Inorganic Networks: A Unique Case of Heterometallic Cation-Cation Interaction with UVI=O-LnIII Bonding (Ln = Ce, Nd). J. Am. Chem. Soc. 2011, 134 (2), 12751283. https://doi.org/10.1021/JA209915N.

(16) Tian, T.; Yang, W.; Pan, Q.-J.; Sun, Z.-M. The First Uranyl Arsonates Featuring Heterometallic Cation-Cation Interactions with UVI=O-ZnII Bonding. Inorg. Chem. 2012, 51 (20), 11150 11154. https://doi.org/10.1021/IC3017479.

(17) Tian, T.; Yang, W.; Wang, H.; Dang, S.; Sun, Z.-M. Flexible Diphosphonic Acids for the Isolation of Uranyl Hybrids with Heterometallic UVI=O-ZnII Cation-Cation Interactions. Inorg. Chem. 2013, 52 (15), 8288-8290. https://doi.org/10.1021/IC4009834.

(18) Groom, C. R.; Bruno, I. J.; Lightfoot, M. P.; Ward, S. C. The Cambridge Structural Database. Acta Crystallogr. Sect. B Struct. Sci. Cryst. Eng. Mater. 2016, 72 (2), 171-179. https://doi.org/10.1107/S2052520616003954.

(19) Thuéry, P.; Harrowfield, J. Variations on the Honeycomb Topology: From Triangular- and Square-Grooved Networks to Tubular Assemblies in Uranyl Tricarballylate Complexes. Cryst. Growth Des. 2017, 17 (3), 963-966. https://doi.org/10.1021/acs.cgd.7b00126.

(20) Thuéry, P.; Harrowfield, J. AgI and PbII as Additional Assembling Cations in Uranyl Coordination Polymers and Frameworks. Cryst. Growth Des. 2017, 17 (4), 2116-2130. https://doi.org/10.1021/acs.cgd.7b00081.

(21) Thuéry, P.; Harrowfield, J. Structural Consequences of 1,4-Cyclohexanedicarboxylate Cis/Trans Isomerism in Uranyl Ion Complexes: From Molecular Species to 2D and 3D Entangled Nets. Inorg. Chem. 2017, 56 (21), 13464-13481. https://doi.org/10.1021/acs.inorgchem.7b02176.

(22) Thuéry, P.; Harrowfield, J. Modulation of the Structure and Properties of Uranyl Ion Coordination Polymers Derived from 1,3,5-Benzenetriacetate by Incorporation of $\mathrm{Ag}(\mathrm{I})$ or $\mathrm{Pb}(\mathrm{II})$. Inorg. Chem. 2016, 55 (13), 6799-6816. https://doi.org/10.1021/acs.inorgchem.6b01168.

(23) Thuéry, P.; Harrowfield, J. Uranyl Ion Complexes with Chiral Malic and Citramalic, and Prochiral Citric and Tricarballylic Acids: Influence of Coligands and Additional Metal Cations. Eur. J. Inorg. Chem. 2018, 2018 (8), 1016-1027. https://doi.org/10.1002/ejic.201701406.

(24) Thuéry, P.; Harrowfield, J. Tetrahydrofurantetracarboxylic Acid: An Isomerizable FrameworkForming Ligand in Homo- and Heterometallic Complexes with $\mathrm{UO} 22+, \mathrm{Ag}+$, and $\mathrm{Pb} 2+$. Cryst. Growth Des. 2016, 16 (12), 7083-7093. https://doi.org/10.1021/acs.cgd.6b01312.

(25) Zhao, R.; Mei, L.; Hu, K. Q.; Tian, M.; Chai, Z. F.; Shi, W. Q. Bimetallic Uranyl Organic Frameworks Supported by Transition-Metal-Ion-Based Metalloligand Motifs: Synthesis, Structure Diversity, and Luminescence Properties. Inorg. Chem. 2018, 57 (10), 6084-6094. https://doi.org/10.1021/acs.inorgchem.8b00634.

(26) Thuéry, P.; Rivière, E.; Harrowfield, J. Uranyl and Uranyl-3d Block Cation Complexes with 1,3Adamantanedicarboxylate: Crystal Structures, Luminescence, and Magnetic Properties. Inorg. Chem. 2015, 54 (6), 2838-2850. https://doi.org/10.1021/ic503004j.

(27) Thuéry, P.; Harrowfield, J. Uranyl Ion Complexes with 1,1'-Biphenyl-2,2',6,6'-Tetracarboxylic Acid: Structural and Spectroscopic Studies of One- to Three-Dimensional Assemblies. Inorg. Chem. 2015, 54 (13), 6296-6305. https://doi.org/10.1021/acs.inorgchem.5b00596.

(28) Adelani, P. O.; Albrecht-Schmitt, T. E. Heterobimetallic Copper(II) Uranyl Carboxyphenylphosphonates. Cryst. Growth Des. 2011, 11 (10), 4676-4683. https://doi.org/10.1021/cg200978y.

(29) Thuéry, P.; Harrowfield, J. Chiral One- to Three-Dimensional Uranyl-Organic Assemblies from (1R,3S)-(+)-Camphoric Acid. CrystEngComm 2014, 16 (14), 2996-3004. https://doi.org/10.1039/c3ce42613k.

(30) Wang, S.; Parker, T. G.; Grant, D. J.; Diwu, J.; Alekseev, E. V.; Depmeier, W.; Gagliardi, L.; Albrecht-Schmitt, T. E. Elucidation of Tetraboric Acid with a New Borate Fundamental Building 
Block in a Chiral Uranyl Fluoroborate. Inorg. Chem. 2012, 51 (21), 11211-11213. https://doi.org/10.1021/ic300741s.

(31) Kerr, A. T.; Cahill, C. L. Postsynthetic Rearrangement/Metalation as a Route to Bimetallic Uranyl Coordination Polymers: Syntheses, Structures, and Luminescence. Cryst. Growth Des. 2014, 14 (4), 1914-1921. https://doi.org/10.1021/cg500050q.

(32) Basile, M.; Unruh, D. K.; Streicher, L.; Forbes, T. Z. Spectral Analysis of the Uranyl Squarate and Croconate System: Evaluating Differences between the Solution and Solid-State Phases. Cryst.

Growth Des. 2017, 17 (10), 5330-5341. https://doi.org/10.1021/acs.cgd.7b00838.

(33) Natrajan, L. S. Developments in the Photophysics and Photochemistry of Actinide Ions and Their Coordination Compounds. Coordination Chemistry Reviews. Elsevier August 1, 2012, pp 15831603. https://doi.org/10.1016/j.ccr.2012.03.029.

(34) Nguyen-Trung, C.; Begun, G. M.; Palmer, D. A. Aqueous Uranium Complexes. 2. Raman Spectroscopic Study of the Complex Formation of the Dioxouranium(VI) Ion with a Variety of Inorganic and Organic Ligands. Inorg. Chem 1992, 31, 5280-5287.

(35) Lu, G.; Haes, A. J.; Forbes, T. Z. Detection and Identification of Solids, Surfaces, and Solutions of Uranium Using Vibrational Spectroscopy. Coordination Chemistry Reviews. Elsevier B.V.

November 1, 2018, pp 314-344. https://doi.org/10.1016/j.ccr.2018.07.010.

(36) Bruker. APEXIII. Bruker AXS Inc.: Madison, Wisconsin, USA 2020.

(37) Bruker. BIS. Bruker AXS Inc.: Madison, Wisconsin, USA 2020.

(38) SAINT Version 8.34a. Bruker AXS Inc. Madison, WI, WI 2013.

(39) Sheldrick, G. M. SADABS. University of Göttingen: Göttingen, Germany 2005.

(40) Sheldrick, G. M. A Short History of SHELX. Acta Crystallogr. Sect. A 2008, 64, 112-122. https://doi.org/10.1107/S0108767307043930.

(41) Huebschle, C. B.; Sheldrick, G. M.; Dittrich, B. ShelXle: A Qt Graphical User Interface for SHELXL. J. Appl. Crystallogr. 2011, 44 (6), 1281-1284. https://doi.org/10.1107/S0021889811043202.

(42) CrystalMaker, 8.2.2 Ed. Crystal Maker Software Limited: Bicester, England 2009.

(43) Putz, H. Match! Phase Identification from Powder Diffraction. Crystal Impact: Bonn, Germany.

(44) Frisch, M. J.; Trucks, G. W.; Schlegel, H. B.; Scuseria, G. E.; Robb, M. A.; Cheeseman, J. R.; Scalmani, G.; Barone, V.; Petersson, G. A.; Nakatsuji, H.; Li, X.; Caricato, M.; Marenich, A. V.; Bloino, J.; Janesko, B. G.; Gomperts, R.; Mennucci, B.; Hratchian, H. P.; Ortiz, J. V.; Izmaylov, A. F.; Sonnenberg, J. L.; Williams-Young, D.; Ding, F.; Lipparini, F.; Egidi, F.; Goings, J.; Peng, B.; Petrone, A.; Henderson, T.; Ranasinghe, D.; Zakrzewski, V. G.; Gao, J.; Rega, N.; Zheng, G.; Liang, W.; Hada, M.; Ehara, M.; Toyota, K.; Fukuda, R.; Hasegawa, J.; Ishida, M.; Nakajima, T.; Honda, Y.; Kitao, O.; Nakai, H.; Vreven, T.; Throssell, K.; Montgomery, J. A., J.; Peralta, J. E.; Ogliaro, F.; Bearpark, M. J.; Heyd, J. J.; Brothers, E. N.; Kudin, K. N.; Staroverov, V. N.; Keith, T. A.; Kobayashi, R.; Normand, J.; Raghavachari, K.; Rendell, A. P.; Burant, J. C.; Iyengar, S. S.; Tomasi, J.; Cossi, M.; Millam, J. M.; Klene, M.; Adamo, C.; Cammi, R.; Ochterski, J. W.; Martin, R. L.; Morokuma, K.; Farkas, O.; Foresman, J. B.; Fox, D. J. Gaussian 16, Revision B.01, Gaussian, Inc., Wallingford CT. 2016.

(45) Weigend, F. Accurate Coulomb-Fitting Basis Sets for H to Rn. Phys. Chem. Chem. Phys. 2006, 8 (9), 1057-1065. https://doi.org/10.1039/b515623h.

(46) Becke, A. D. Density-Functional Thermochemistry. III. The Role of Exact Exchange. J. Chem. Phys. 1993, 98 (7), 5648-5652. https://doi.org/10.1063/1.464913.

(47) Weigend, F.; Ahlrichs, R. Balanced Basis Sets of Split Valence, Triple Zeta Valence and Quadruple Zeta Valence Quality for H to Rn: Design and Assessment of Accuracy. Phys. Chem. Chem. Phys. 2005, 7 (18), 3297-3305. https://doi.org/10.1039/b508541a.

(48) Cao, X.; Dolg, M.; Stoll, H. Valence Basis Sets for Relativistic Energy-Consistent Small-Core Actinide Pseudopotentials. J. Chem. Phys. 2003, 118 (2), 487-496.

https://doi.org/10.1063/1.1521431.

(49) Cao, X.; Dolg, M. Segmented Contraction Scheme for Small-Core Actinide Pseudopotential Basis 
Sets. J. Mol. Struct. THEOCHEM 2004, 673 (1-3), 203-209.

https://doi.org/10.1016/j.theochem.2003.12.015.

(50) Küchle, W.; Dolg, M.; Stoll, H.; Preuss, H. Energy-Adjusted Pseudopotentials for the Actinides. Parameter Sets and Test Calculations for Thorium and Thorium Monoxide. J. Chem. Phys. 1994, 100 (10), 7535-7542. https://doi.org/10.1063/1.466847.

(51) Bader, R. F. W. Atoms in Molecules: A Quantum Theory; Oxford University Press: Oxford, UK, 1990.

(52) Keith, T. A. AIMAll, Version 19.10.12. TK Gristmall Software: Overland Park, Kansas, USA 2019.

(53) Bondi, A. Van Der Waals Volumes and Radii. J. Phys. Chem. 1964, 68 (3), 441-451. https://doi.org/10.1021/j100785a001.

(54) Arnold, P. L.; Pécharman, A.-F.; Lord, R. M.; Jones, G. M.; Hollis, E.; Nichol, G. S.; Maron, L.; Fang, J.; Davin, T.; Love, J. B. Control of Oxo-Group Functionalization and Reduction of the Uranyl Ion. Inorg. Chem. 2015, 54 (7), 3702-3710.

https://doi.org/10.1021/ACS.INORGCHEM.5B00420.

(55) Pietro, P. Di; Kerridge, A. Assessing Covalency in Equatorial U-N Bonds: Density Based Measures of Bonding in BTP and Isoamethyrin Complexes of Uranyl. Phys. Chem. Chem. Phys. 2016, 18 (25), 16830-16839. https://doi.org/10.1039/C6CP01273F.

(56) Surbella, R. G.; Cahill, C. L. The Exploration of Supramolecular Interactions Stemming from the [UO 2(NCS)4(H2O)]2- Tecton and Substituted Pyridinium Cations. CrystEngComm 2014, 16 (12), 2352-2364. https://doi.org/10.1039/c3ce42106f.

(57) Denning, R. G. Electronic Structure and Bonding in Actinyl Ions and Their Analogs. J. Phys. Chem. A 2007, 111 (20), 4125-4143. https://doi.org/10.1021/jp071061n.

(58) Carter, K. P.; Kalaj, M.; Surbella, R. G.; Ducati, L. C.; Autschbach, J.; Cahill, C. L. Engaging the Terminal: Promoting Halogen Bonding Interactions with Uranyl Oxo Atoms. Chem. - A Eur. J. 2017, 23 (61), 15355-15369. https://doi.org/10.1002/chem.201702744.

(59) Carter, K. P.; Kalaj, M.; Kerridge, A.; Cahill, C. L. Probing Hydrogen and Halogen-Oxo Interactions in Uranyl Coordination Polymers: A Combined Crystallographic and Computational Study. CrystEngComm 2018, 20 (34), 4916-4925. https://doi.org/10.1039/c8ce00682b.

(60) Kalaj, M.; Carter, K. P.; Cahill, C. L. Isolating Equatorial and Oxo Based Influences on Uranyl Vibrational Spectroscopy in a Family of Hybrid Materials Featuring Halogen Bonding Interactions with Uranyl Oxo Atoms. Eur. J. Inorg. Chem. 2017, 2017 (40), 4702-4713. https://doi.org/10.1002/ejic.201700788.

(61) John Wiley \& Sons, I. SpectraBase.

(62) A. Kerridge. Quantification of F-Element Covalency through Analysis of the Electron Density: Insights from Simulation. Chem. Commun. 2017, 53 (50), 6685-6695. https://doi.org/10.1039/C7CC00962C.

(63) Pietro, P. Di; Kerridge, A. Assessing Covalency in Equatorial U-N Bonds: Density Based Measures of Bonding in BTP and Isoamethyrin Complexes of Uranyl. Phys. Chem. Chem. Phys. 2016, 18 (25), 16830-16839. https://doi.org/10.1039/C6CP01273F.

(64) Pietro, P. Di; Kerridge, A. U-Oyl Stretching Vibrations as a Quantitative Measure of the Equatorial Bond Covalency in Uranyl Complexes: A Quantum-Chemical Investigation. Inorg. Chem. 2015, 55 (2), 573-583. https://doi.org/10.1021/ACS.INORGCHEM.5B01219.

(65) Serezhkina, L. B.; Peresypkina, E. V.; Virovets, A. V.; Neklyudova, N. A. Synthesis and X-Ray Diffraction Study of $\mathrm{R}[\mathrm{UO} 2(\mathrm{CH} 3 \mathrm{COO}) 3](\mathrm{R}=\mathrm{H} 3 \mathrm{O}+$ or $\mathrm{NH}(\mathrm{C} 2 \mathrm{H} 5) 3+)$. Russ. J. Inorg. Chem. 2010, 55 (7), 1020-1025. https://doi.org/10.1134/S0036023610070065. 